University of Tennessee Health Science Center

UTHSC Digital Commons

\title{
The Traditional Roles of Caring for Elders: Views from First Nations Elders Regarding Health, Violence, and Elder Abuse
}

\author{
Eileen A. Owen-Williams \\ University of Tennessee Health Science Center
}

Follow this and additional works at: https://dc.uthsc.edu/dissertations

Part of the Mental and Social Health Commons

\section{Recommended Citation}

Owen-Williams, Eileen A. , "The Traditional Roles of Caring for Elders: Views from First Nations Elders Regarding Health, Violence, and Elder Abuse" (2012). Theses and Dissertations (ETD). Paper 190. http://dx.doi.org/10.21007/etd.cghs.2012.0232. 


\title{
The Traditional Roles of Caring for Elders: Views from First Nations Elders Regarding Health, Violence, and Elder Abuse
}

\author{
Abstract \\ This study sought to respectfully understand Northern British Columbia First Nations Elders' views \\ regarding health of communities, intergenerational relationships, Elder roles, and violence towards Elders. \\ Injuries, both intentional and unintentional, are a leading cause of death for First Nations Peoples. \\ Information regarding Elder abuse in First Nations communities is lacking, though family violence has \\ been identified as a problem within First Nations communities. The goal of this research was to \\ understand the point of view and Elders' reality through the creation of a dialogue with Elders, and to \\ discern the interface between Traditional First Nations' belief systems, healing methods, and current legal \\ and health care systems within Canada.
}

This study used a community-based participatory research design to explore social and cultural context through the views of Carrier Sekani Elders in the Ts'il Kaz Koh community. The design acted to support the aims of the study which were: To explore how First Nations Elders understand violence in their communities, to explore what First Nations Elders believe gives rise to violence in First Nations communities; to illuminate the factors that First Nations Elder view as affecting the safety and well-being of Elders living in First Nations communities; to explore First Nations Elders' narration of intergenerational relationships before and after contact; and to make clear factors which First Nations Elders view as required for Elders to remain safe and stay within their respective communities.

The study followed the CIHR Guidelines for Research with Aboriginal Peoples. Approval was obtained from Carrier Sekani Family Services' Research Review Committee, from the Ts'il Kaz Koh Chief and Council and Ts'il Kaz Koh Community, the Ethics Review Board of the University of Northern British Columbia, and the Institutional Review Board of the University of Tennessee. Informed consent was obtained both from the Ts'il Kaz Koh community and from participating Elders, utilizing Ts'il Kaz Koh cultural protocol. Six Ts'il Kaz Koh Elders residing in Northern British Columbia participated in interviews utilizing an interview guide. Interviews were then read, categorized, and coded according to identified concepts, allowing for retrieval of themes. Codes were submitted to two committee members for review and consensus regarding the categories of each code for reliability. Both a domain analysis and a taxonomic analysis were performed on the data. A convergent analysis of themes was performed to assure internal and external validity. The findings were presented to the Elders at each step of the analysis to ensure validity and reliability. The final document was presented to the community to ensure that all information was accurate and acceptable to the community.

Limitations of the study include the limited sample of Elders solely from the Ts'il Kaz Koh (Burns Lake) community. This limitation is also viewed as an opportunity for the Ts'il Kaz Koh to request program development funding as a pilot initiative. This sample limited to one First Nations community prohibits the generalization of findings to other communities until further research occurs with other communities.

Themes related to the problems of violence were multiple, including changes from Traditional way of living to contemporary way of life, changes from the Residential School experience, loss of Traditional roles, and change in community from communal structure to that of nuclear family units, and the influence of alcohol and drugs on individuals and families. Sub-themes related to violence included the loss of intergenerational relationships, changes in Elder roles from the past, and the change in roles and behavior from the past across all ages. Also identified as sub-themes were the influences of change from that of communal caring, to individuals watching out for their own welfare, and the change from hard work being valued within Traditional roles to lack of value for hard work in contemporary society. Disruption of intergeneration roles within the community was also identified as a theme related to 
violence.

Recommendations from this study include the need to further research the views of Elders surrounding violence and Elder abuse in other First Nations communities, with translation to clinical practice and the development of a culturally appropriate screening tool for First Nations Elder safety and abuse. Further research with other First Nations communities will allow generalization of results to be utilized in program development and evaluation. This study supports the utilization of the health determinants model in program planning and the developing of capacity for First Nations to control their health care services. The findings of this study also support the need for funding of Youth-Elder initiatives which foster the reestablishment of intergenerational relationships and the concurrent translation of Elders' Traditional knowledge. Utilizing Elders as leaders and a source of Traditional health knowledge is part of a viable model of combining contemporary and Traditional health care practices. The Elders' views supported the importance of a strength-based approach to healing with the prior work of McCormick who found that effective healing for First Nations people must have a focus on "interconnectedness" rather than personal autonomy in order for communities to heal. This study would like to acknowledge the strength of these Elders and the Ts'il Kaz Koh community to deal with the historical trauma of Residential Schools and the effects on individual, family and community health.

\section{Document Type}

Dissertation

\section{Degree Name}

Doctor of Philosophy (PhD)

\section{Program}

Nursing

\section{Research Advisor}

Michael Carter, DNSc, DNP

\section{Keywords}

Community Participatory Research, Determinants of Health, Elder Abuse First Nations, Intergenerational Relationships, Residential Schools

\section{Subject Categories}

Medicine and Health Sciences | Mental and Social Health 
The Traditional Roles of Caring for Elders: Views from First Nations Elders

Regarding Health, Violence, and Elder Abuse

\author{
A Dissertation \\ Presented for \\ The Graduate Studies Council \\ The University of Tennessee \\ Health Science Center
}

\begin{abstract}
In Partial Fulfillment
Of the Requirements for the Degree

Doctor of Philosophy

From The University of Tennessee
\end{abstract}

By

Eileen A. Owen-Williams

May 2012 
Copyright (C) 2012 by Eileen A. Owen-Williams.

All rights reserved. 


\section{DEDICATION}

This dissertation is dedicated to the health and well-being of all people, both Aboriginal and non-Aboriginal. 


\section{ACKNOWLEDGEMENTS}

I would like to acknowledge my wonderful chair, Dr. Michael Carter who has been my mentor and guide through two doctoral degrees at The University of Tennessee Health Science Center (UTHSC). Michael, you gave me strength, when I could not find any over the years and helped me to see through a new lens of scholarship. I would also like to acknowledge the faculty and staff of the UTHSC College of Nursing and my incredible committee who always had time to review my submissions, provide thoughtful feedback, and guide me to the next level of scholarship. Thank you, Dr. Carolyn Graff, Dr. Carol Lockhart, and Dr. Patricia Speck. A special thanks to Dr. Antonia Mills for her gentle teaching and guidance with First Nation's epistemology and her support of my learning, while empowering me as a researcher.

I would like to thank Dr. Travis Holyk for his partnership and support of this research, as well as the staff at Carrier Sekani Family Services, including Mabel Louie, Health Director of Carrier Sekani Family Services, Benna Rathburn at Prince George, Syndee George and Cheryl Boyd at the Burns Lake office. I would also like to express my heartfelt thanks to Dr. Tina Fraser for her mentoring regarding cultural protocol and for welcoming me as a non-Indigenous researcher into the realm and the privilege of Indigenous research.

I acknowledge the Pacific Northwest Canadian Studies Consortium who granted my travel money for a trip to Northern British Columbia to interview for my dissertation.

A hearty thanks to Chief Gerow who supported my research and welcomed me into the community to work with the Elders of Ts'il Kaz Koh. I thank Chief Gerow and the Band Council as well as the entire Ts'il Kaz Koh community for their approval and support.

I give my heartfelt appreciation to the Elders and Junior Elders of the Ts'il Kaz Koh community, including Ruth Tibbetts, Peter John, Ed Gerow, Frank Tibbets, Cecelia Sam, and Robert Charlie. Thank you for your trust, for sharing your wisdom, and for your stories from the heart.

I would like to acknowledge my friends, colleagues, and family for their support

and patience as I completed this doctorate. To my mother who is 96 and enjoying life and my sister Mary and my nephew Connor who fed me over the years; thank you. A special thank you and acknowledgment goes to my children, Elizabeth, Robert, my daughter-inlaw Maude, and my granddaughter Parrish. You are the great joy of my life. 


\begin{abstract}
This study sought to respectfully understand Northern British Columbia First Nations Elders' views regarding health of communities, intergenerational relationships, Elder roles, and violence towards Elders. Injuries, both intentional and unintentional, are a leading cause of death for First Nations Peoples. Information regarding Elder abuse in First Nations communities is lacking, though family violence has been identified as a problem within First Nations communities. The goal of this research was to understand the point of view and Elders' reality through the creation of a dialogue with Elders, and to discern the interface between Traditional First Nations' belief systems, healing methods, and current legal and health care systems within Canada.

This study used a community-based participatory research design to explore social and cultural context through the views of Carrier Sekani Elders in the Ts'il Kaz Koh community. The design acted to support the aims of the study which were: To explore how First Nations Elders understand violence in their communities, to explore what First Nations Elders believe gives rise to violence in First Nations communities; to illuminate the factors that First Nations Elder view as affecting the safety and well-being of Elders living in First Nations communities; to explore First Nations Elders' narration of intergenerational relationships before and after contact; and to make clear factors which First Nations Elders view as required for Elders to remain safe and stay within their respective communities.
\end{abstract}

The study followed the CIHR Guidelines for Research with Aboriginal Peoples. Approval was obtained from Carrier Sekani Family Services' Research Review Committee, from the Ts'il Kaz Koh Chief and Council and Ts'il Kaz Koh Community, the Ethics Review Board of the University of Northern British Columbia, and the Institutional Review Board of the University of Tennessee. Informed consent was obtained both from the Ts'il Kaz Koh community and from participating Elders, utilizing Ts'il Kaz Koh cultural protocol. Six Ts'il Kaz Koh Elders residing in Northern British Columbia participated in interviews utilizing an interview guide. Interviews were then read, categorized, and coded according to identified concepts, allowing for retrieval of themes. Codes were submitted to two committee members for review and consensus regarding the categories of each code for reliability. Both a domain analysis and a taxonomic analysis were performed on the data. A convergent analysis of themes was performed to assure internal and external validity. The findings were presented to the Elders at each step of the analysis to ensure validity and reliability. The final document was presented to the community to ensure that all information was accurate and acceptable to the community.

Limitations of the study include the limited sample of Elders solely from the Ts'il Kaz Koh (Burns Lake) community. This limitation is also viewed as an opportunity for the Ts'il Kaz Koh to request program development funding as a pilot initiative. This sample limited to one First Nations community prohibits the generalization of findings to other communities until further research occurs with other communities. 
Themes related to the problems of violence were multiple, including changes from Traditional way of living to contemporary way of life, changes from the Residential School experience, loss of Traditional roles, and change in community from communal structure to that of nuclear family units, and the influence of alcohol and drugs on individuals and families. Sub-themes related to violence included the loss of intergenerational relationships, changes in Elder roles from the past, and the change in roles and behavior from the past across all ages. Also identified as sub-themes were the influences of change from that of communal caring, to individuals watching out for their own welfare, and the change from hard work being valued within Traditional roles to lack of value for hard work in contemporary society. Disruption of intergeneration roles within the community was also identified as a theme related to violence.

Recommendations from this study include the need to further research the views of Elders surrounding violence and Elder abuse in other First Nations communities, with translation to clinical practice and the development of a culturally appropriate screening tool for First Nations Elder safety and abuse. Further research with other First Nations communities will allow generalization of results to be utilized in program development and evaluation. This study supports the utilization of the health determinants model in program planning and the developing of capacity for First Nations to control their health care services. The findings of this study also support the need for funding of Youth-Elder initiatives which foster the re-establishment of intergenerational relationships and the concurrent translation of Elders' Traditional knowledge. Utilizing Elders as leaders and a source of Traditional health knowledge is part of a viable model of combining contemporary and Traditional health care practices. The Elders' views supported the importance of a strength-based approach to healing with the prior work of McCormick who found that effective healing for First Nations people must have a focus on "interconnectedness" rather than personal autonomy in order for communities to heal. This study would like to acknowledge the strength of these Elders and the Ts'il Kaz Koh community to deal with the historical trauma of Residential Schools and the effects on individual, family and community health. 


\section{TABLE OF CONTENTS}

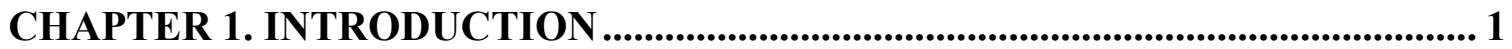

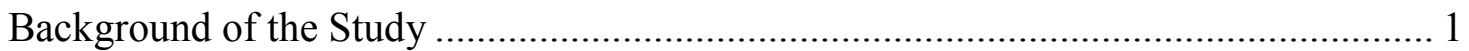

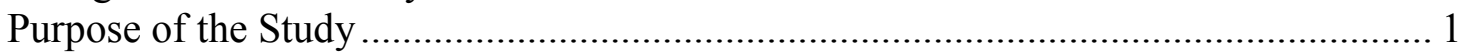

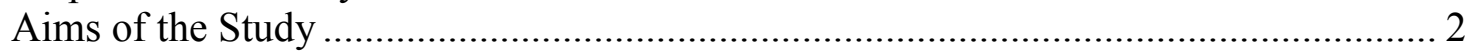

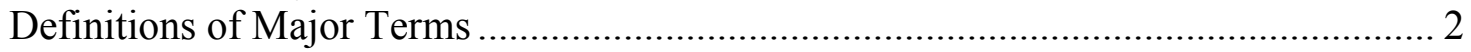

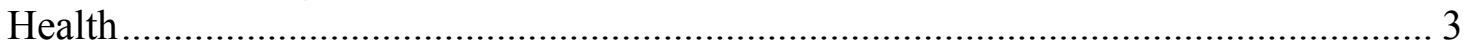

External Determinants of Health within First Nations Communities ........................... 4

Health Care Delivery to British Columbia First Nations Communities ........................ 7

First Nations Epistemology and Conceptual Framework ............................................ 8

Traditional roles of Elders in First Nations communities ..................................... 8

The spiritual nature of Aboriginal research ......................................................... 9

CHAPTER 2. REVIEW OF LITERATURE ............................................................ 11

Northern British Columbia and Canada...................................................................... 11

Carrier Sekani Tribal Council and Carrier Sekani Family Services ........................... 11

Disruption of First Nations Ways of Life, Historical Trauma and Violence................ 13

Traditional First Nations Roles ........................................................................ 15

Indigenous Health Disparities Related to Intentional and Unintentional Injury ......... 16

Violence against Aboriginal Women..................................................................... 19

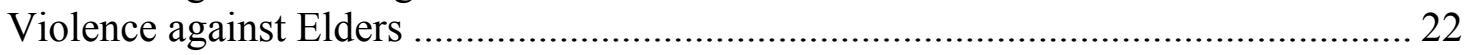

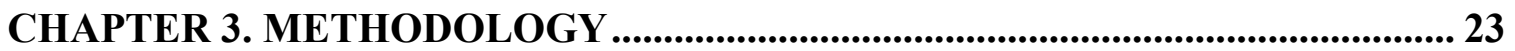

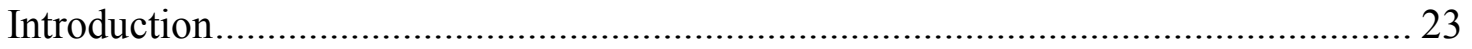

Community Based Participatory Research Methodology ........................................ 23

Design and Setting ............................................................................................ 24

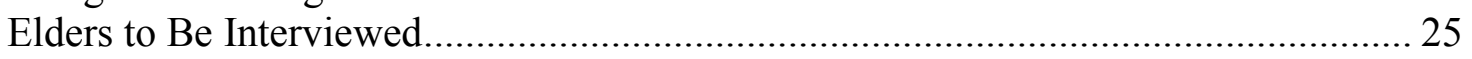

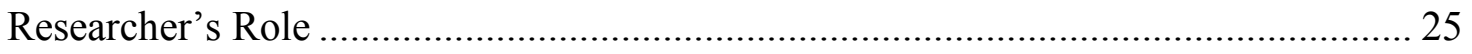

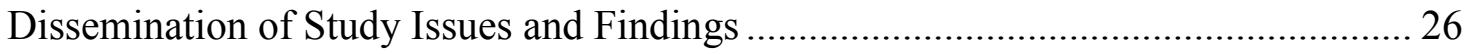

Protection of Human Subjects ............................................................................. 27

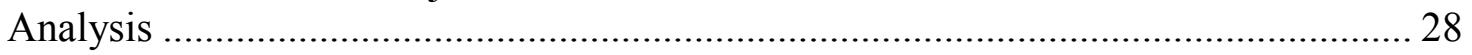

CHAPTER 4. INTERVIEW FINDINGS............................................................... 31

Interviews with Burns Lake Elders.................................................................... 31

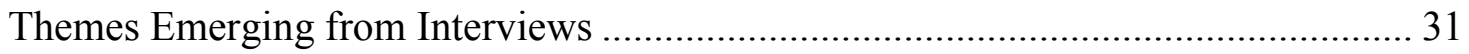

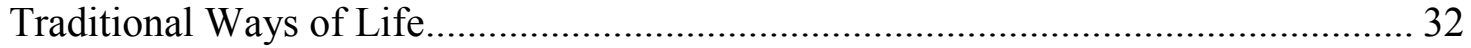

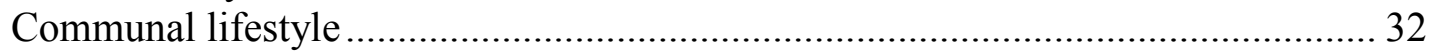

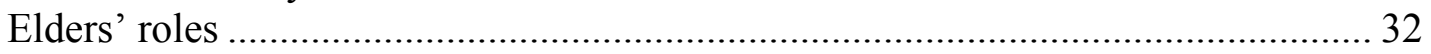

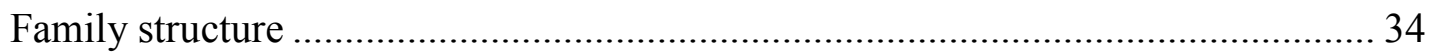

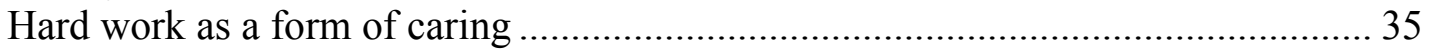

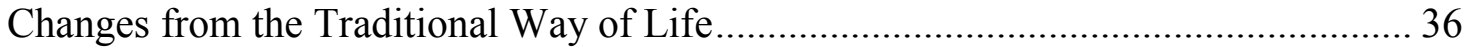

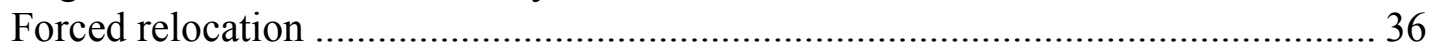




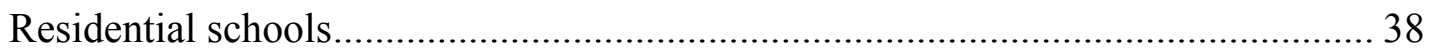

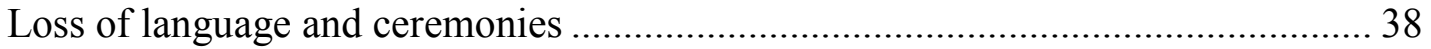

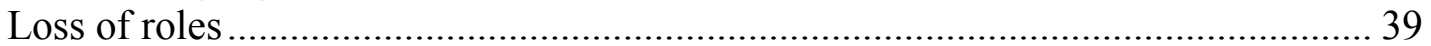

Loss of communal structure and values ......................................................... 39

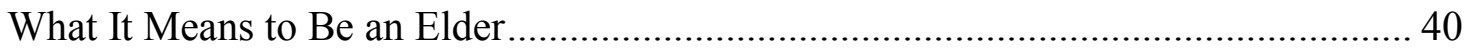

Balancing Traditional and Christian beliefs......................................................... 41

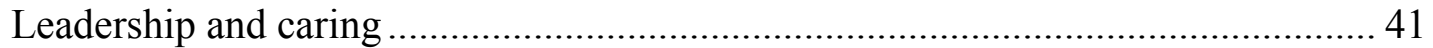

Keepers of Traditional knowledge ................................................................ 42

Current Family Characteristics .......................................................................... 42

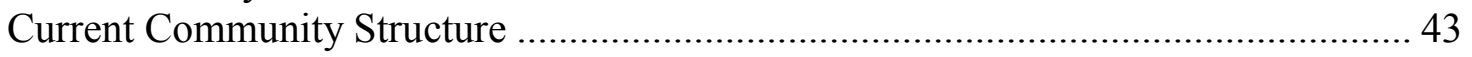

Violence Affecting Elders ................................................................................. 43

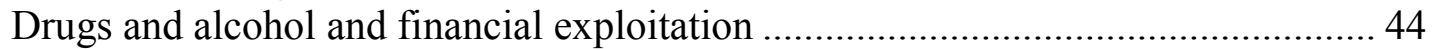

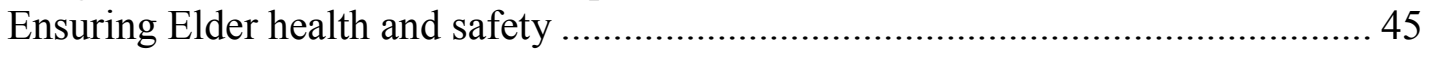

CHAPTER 5. LESSONS LEARNED FROM THE ELDERS................................ 48

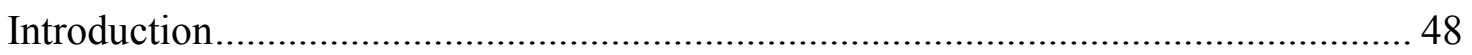

Findings Related to the Aims of the Study ............................................................. 48

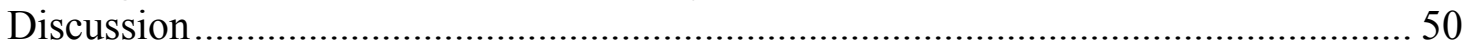

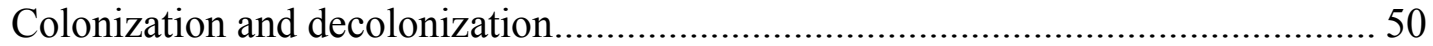

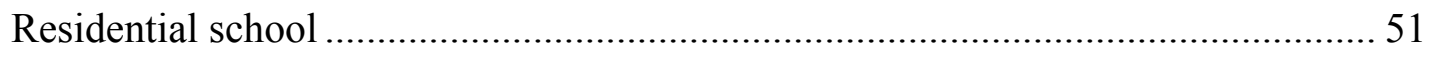

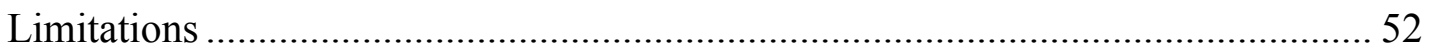

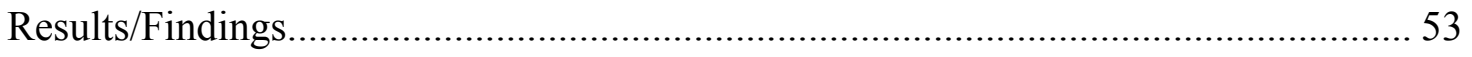

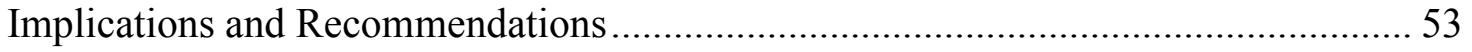

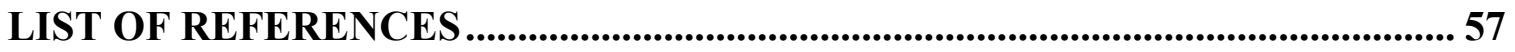

APPENDIX A. INSTITUTIONAL REVIEW BOARD APPROVAL FROM THE UNIVERSITY OF TENNESSEE HEALTH SCIENCE

CENTER.................................................................................64

APPENDIX B. RESEARCH ETHICS BOARD APPROVAL FROM THE UNIVERSITY OF NORTHERN BRITISH COLUMBIA ..............66

APPENDIX C. INTERVIEW QUESTIONS ....................................................67

VITA 


\section{LIST OF FIGURES}

Figure 1-1. First Nations wholistic policy and planning model ..................................5

Figure 2-1. Age-standardized injury death rate for selected provinces, 1996-1997.......17

Figure 2-2. Crude suicide death rate by age group for First Nations and Canadian

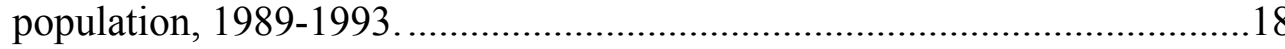

Figure 2-3. External causes of death: B.C. status Indian population, 1991-1998. .........20

Figure 2-4. Rates of spousal homicide, by sex of victim and Aboriginal status, 1997 to 2000

Figure 4-1. Carrier Sekani traditional territory and Indian reserves................................... 


\section{CHAPTER 1. INTRODUCTION}

\section{Background of the Study}

Between the fall of 2006 and the summer of 2008, I had the privilege of working as a Nurse Practitioner at the Central Interior Native Health Society in Prince George, British Columbia. During my time at the clinic, I talked with First Nations Elders ${ }^{1}$ who expressed concern over the effect of violence on many of the Elders in Northern British Columbia, and loss of traditional family roles. I was told that both the increased rate of drug use among some of the younger members of First Nations families and the need for families to move away from Traditional lands to seek jobs were causing many Elders to become isolated from their communities and Traditional lands. Another factor of concern to many was the disbursement of Residential School payments (settlement money) fearing that this federal money paid to the Elders who survived the Residential Schools would be spent by younger family members on drugs. I was told that the Elders would not report this loss of funds outside of their families, because it was a private matter, but would suffer in silence.

My clinical background is one as a Forensic Nurse and a Family Nurse Practitioner, who has been involved in abuse and violence within families for over 30 years. I have specialized in elder abuse in my doctoral studies at the University of Tennessee where I am a current student, completing a second doctorate in nursing research. While working in Canada, I had experienced the success of a mixed model of Traditional and Western medical model of care within the Central Interior Native Health Society and within the Anishnawbe Clinic in Toronto. These experiences, and a calling, have moved me to respectfully request a partnership with the Carrier Sekani to look into the issues of Elder health, Traditional knowledge, intergenerational relationships, and violence; so as to seek the wisdom of the Elders in regard to addressing these issues from a strength-based focus. While I taught nursing at the University of Northern British Columbia, I had the opportunity to work with many First Nations Studies professors and researchers, and have been fortunate to currently have Dr. Antonia Mills as a member of my doctoral committee. These experiences have helped guide me along this knowledge journey. Since beginning to study Elder health issues, I have moved to Seattle to care for my mother who became ill in 2008. Though I do not currently reside in the Prince George area, I am still called in my heart to look into First Nation Elder health and well-being in Northern British Columbia.

\section{Purpose of the Study}

In this study, I sought to respectfully understand Northern British Columbia First Nations Elders' views regarding health of communities, intergenerational relationships, Elder roles, and violence. The goals of this study were to create a dialogue between

\footnotetext{
${ }^{1}$ Note: In a show of respect, the words Elder, Western, Indigenous, and Traditional will be capitalized throughout this dissertation.
} 
myself and Elders in the Carrier Sekani Family Service area communities to discern how these Elders understood the interface between Traditional First Nations belief systems, healing methods, and the current health care systems within Canada in regard to violence. I hoped that this study would be able to bridge the understanding of the meanings of health and violence within the epistemology of First Nations' culture through a research partnership with the Carrier Sekani Family Services. It was hoped that a thoughtful translation of knowledge would act to advance the health and safety of Elders within First Nations' communities.

\section{Aims of the Study}

This study had five primary aims.

- $\quad$ Aim 1 is to explore how First Nations Elders understand violence in their communities.

- $\quad \operatorname{Aim} 2$ is to explore what First Nations Elders believe gives rise to violence in First Nations communities.

- $\quad \operatorname{Aim} 3$ is to illuminate the factors that First Nations Elders view as affecting the safety and well-being of Elders living in First Nations communities.

- $\quad$ Aim 4 is to explore First Nations Elders' narration of intergenerational relationships before and after contact.

- $\quad \operatorname{Aim} 5$ is to make clear factors that First Nations Elders view as required for Elders to remain safe and stay within their respective communities.

\section{Definitions of Major Terms}

The following terms used in this document are defined below.

- $\quad$ Aboriginal Peoples refers to all of the original peoples of Canada and their descendants. Section 35 of the Constitution Act of 1982 specifies that the Aboriginal Peoples in Canada consist of three groups - Indian (First Nations), Inuit and Métis.

- $\quad$ Assembly of First Nations $(A F N)$ is the Canadian organization which represents all First Nations Peoples within Canada. There are over 633 First Nations communities in Canada, according to the Assembly of First Nations website (2012).

- $\quad$ Contact refers to the period of time beginning with the initial contact of First Nations peoples with outside European cultures. This initial contact 
was followed by continuous contact by people from Europe in which the colonizing culture became dominant within North America, accompanied by forced submission and assimilation of First Nations cultures.

- Determinants of Health are those factors which affect peoples' health including social, environmental, cultural, economic, mental, physical, emotional, and spiritual components.

- Indigenous Peoples refers to the original people of Canada. Indigenous is capitalized out of respect in this document when identifying the community of peoples who identify themselves as Inuit, First Nations, and Métis. Indigenous is often interchanged with the term Aboriginal, depending on context.

- Non-status Indians refers to those people who identify themselves as Indians but are not registered or not entitled to register pursuant to the Indian Act of Canada. Many of these individuals are members of First Nations communities.

- On-reserve is a term which describes those First Nations individuals who reside in government sanctioned First Nations communities and are afforded rights as designated in the Constitution act of 1982. According to Indian and Northern Affairs Canada (2006, p. 1), The Indian registration is expected to increase over the 25 years from 2004 to 2029, by 40 percent. The rate of growth of those registered individuals living on-reserve is expected to increase by $62 \%$, from a population of 427,100 to 691,000 in the period of 2004-2029.

- $\quad$ Status is a term used within Canada to recognize those First Nations individuals who are registered under the Indian Act.

- $\quad$ Violence is defined according to the World Health Organization's definition in the 2002 landmark report WHO's World Report on Violence and Health. It reads "The intentional use of physical force or power, threatened or actual, against oneself, another person or against a group or community, which either results in or has a high likelihood of resulting in injury, death, psychological harm, maldevelopment or deprivation" (World Health Organization, 2002, p. 5).

\section{Health}

Health is multifaceted and defined differently within various cultures worldwide. The World Health Organization (2006) has a broad definition of health as "a state of complete physical, mental, and social well-being and not merely the absence of disease, or infirmity." The Public Health Agency of Canada (PHAC) (Public Health Agency of Canada, 2005) has defined health as the result of complex interactions between the social, 
economic, physical and individual determinants of health. PHAC, in conjunction with Aboriginal people within Canada, has extended its model of health to encompass physical, social, emotional and spiritual domains of wellness. The Assembly of First Nations (Assembly of First Nations, 2006b) created a wholistic model of health which broadly encompasses the determinants of health in a cultural context, for utilization in the planning of policy and programs (Figure 1-1).

First Nations Peoples within Canada have defined individual health in the context of the health of their community as the two are considered interdependent. Health is considered in terms of the whole person including internal balance of physical, emotional, mental and spiritual components, as well as balance with the physical environment and the community (Assembly of First Nations, 2006b; Health Canada, 2009; McCormick, 2009).

Indigenous health research has confirmed that the health status of First Nations peoples is much lower than that of other groups in Canada (Driscoll \& Jackson, 2007). The United Nation's Economic and Social Council Resolution 2000/22 acted to establish a permanent forum on Indigenous issues as a means to address global health disparities between dominant cultures and Indigenous peoples. Within this United Nations resolution, provisions were set forth for data collection related to Indigenous health (World Health Organization, 2001).

The Indigenous (original) peoples of Canada are known under the collective term of Aboriginal peoples, which consist of distinct cultural groups with separate languages, practices and beliefs and histories. The Canadian Constitution of 1982, Section 35 (2) defined Aboriginal peoples as either Indian presently referred to as First Nations; Inuit; or Métis. The Inuit are the Aboriginal people of the Arctic and reside in Northern Canadian communities in Nunavut, Northwest Territories, Northern Quebec, Nunavik, and Labrador. Inuit means "the people" in Inuktitut which is the native Inuit language. Métis comprise one-third of the Aboriginal population in Canada. The Métis Nation's historical background relates back to Indian and European unions, resulting in mixed ancestry. First Nations people include Status and Non-status Indian individuals and consist of over one million persons, or $4 \%$ of the Canadian population (Indian and Northern Affairs Canada, 2010). For the purposes of this paper, the terms Aboriginal will be utilized to describe all Indigenous peoples of Canada, and First Nations will be used when referring to Indian Status and Non-status peoples of Canada.

\section{External Determinants of Health within First Nations Communities}

In the past, it was not clear to the Canadian government how best to improve First Nations health within Canada, leading to the formation of a First Nations Health Public Health Advisory Committee through the Assembly of First Nations and the Chief's Committee on Health. This committee assessed public health delivery to First Nations communities with the goal of improving First Nations communities in Canada (Assembly of First Nations, 2005a). 


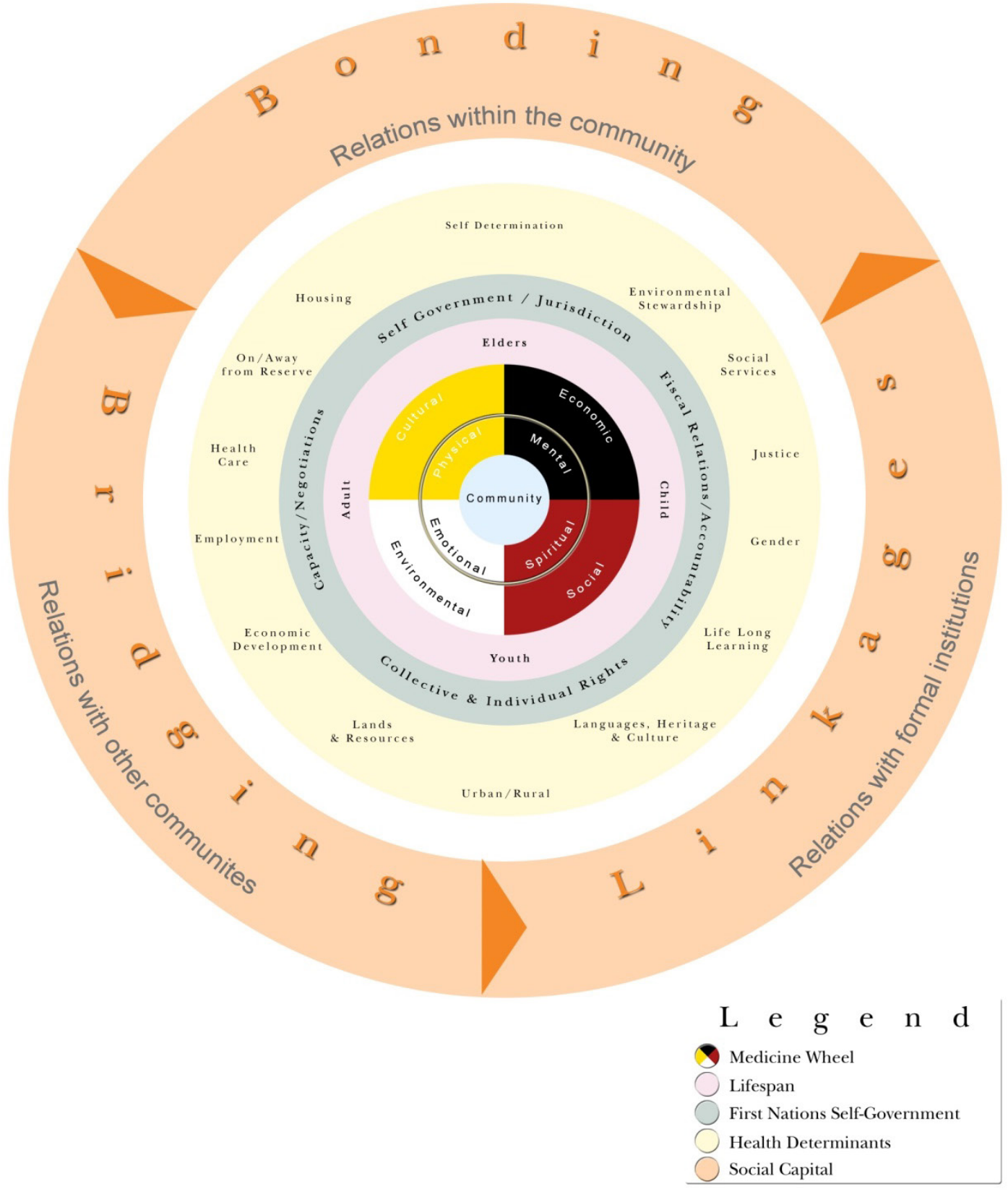

Figure 1-1. First Nations wholistic policy and planning model

Source: Reprinted from Assembly of First Nations. (2006b). First Nations public health: A framework for improving the health of our people and our communities. Retrieved February 23, 2011 from http://64.26.129.156/cmslib/general/FNPB-IH.pdf 
The Assembly of First Nations acted to identify barriers to health services received by First Nations peoples through a comprehensive health assessment of First Nations communities across Canada (First Nations Governance Committee, 2005). This assessment determined that information regarding family violence within First Nations communities was lacking throughout Canada. Additional barriers to health within First Nations communities included lack of adequate health services and epidemiological resources. The assessment also determined that infectious disease surveillance programs were inadequate, and that there was a lack of communication between health care programs and traditional healers, Elders, and First Nations leaders within First Nations communities across Canada. Access to preventative health services for those living on reserve was found to be decreased due to multiple barriers to care including, lack of transportation to health care institutions, availability of services on-reserve, financial restraints, and lack of culturally appropriate services.

The factors that have been identified as negatively impacting First Nations health include lack of adequate housing; increased rates of family separation, disability, illness, and exclusion from mainstream society; as well as high levels of unemployment and poverty (First Nations Governance Committee, 2005). First Nations' unemployment rates on-reserve in 2006 were 23.1\%; almost four times higher than the Canadian rate of $7.3 \%$. In 2001, half (49.7\%) of First Nations youth residing on-reserve at age 20 had not completed high school, as compared to $12 \%$ of the Canadian general population rate in 1999. This limited education contributed to lower incomes within First Nations communities. Twenty-three percent of First Nations populations on-reserve reported incomes under $\$ 5,000$ per person per year compared to only $12 \%$ of the rest of Canadians. The median annual income for First Nations individuals living on-reserve was less than half that of the general Canadian population; $\$ 10,631$ for First Nations onreserve, as compared to $\$ 22,274$ within the Canadian population. (First Nations Governance Committee, 2005; Health Canada, 2009).

Societal roles and associated power differentials inherent to those roles have been related to the subsequent marginalization of First Nations Elders, men, women, and children. Many First Nations women do not have access to housing and property rights in First Nations communities, placing them at risk for homelessness and forced migration to urban areas to seek housing. Many First Nations women do not have their name listed on the official Certificate of Possession for the family home located within a reserve. The Certificate of Possession is the document which deems lawful possession of the reserve lands associated with the house, as described on the certificate. This lack of an authoritative framework to allow recognition of matrimonial real property has caused many First Nations women and children to leave the reserve in search of housing accommodation. Section 28(1) of the Indian Act provides that upon separation or divorce of a couple living on reserve, spouses and children will not be allowed to continue residing in the family home if the spouse is not a member of the band (Assembly of First Nations, 2007). Leaving Traditional communities to seek housing raises concerns regarding the health and safety of these individuals whose homelessness has placed them at increased risk for violent injuries (Assembly of First Nations, 2006b, 2007). 
One quarter of First Nations housing on reserves has been determined to have inadequate or total lack of water services and one fifth of housing has inadequate or lack of sewage services as noted within the 2001 First Nations Assembly assessment (Assembly of First Nations, 2005b). Only half of the sites surveyed under Indian and Northern Affairs Canada had fire services. On-reserve housing was also found to be overcrowded by Western standards and in poor states of repair, further increasing the risk for injury or death due to fire (Indian and Northern Affairs Canada, 2010).

The First Nations Health Reporting Framework (Assembly of First Nations, 2005c) identified intentional and unintentional injuries as the leading cause of premature death and years of life lost within First Nations peoples living on reserves. Health Canada's statistics confirm suicide as the leading cause of death for First Nations individuals between 10 and 44 years of age in 2001, with suicide rates three to four times higher in the Aboriginal population than the general Canadian population (Health Canada, 2001).

\section{Health Care Delivery to British Columbia First Nations Communities}

British Columbia is home to over 200 bands with diverse histories, and over 14 different languages (Chandler \& Lalonde, 2004). Some Bands contract with health authorities for health care, while other Bands provide their own care, and still others receive care from the First Nations and Inuit Branch (FNIB) of the Canadian government. The movement in the last decade has been toward local control and provision of health care policy and services as part of community self-determination. Some communities have formed consortiums to aid in the administration and provision of health care services, such as the group of Bands which constitute the Carrier Sekani Family Services in Northern British Columbia.

The current dominant medical model of health care within Canada is allopathic and disease-focused in structure and process. The difference in epistemology between the medical model and a culturally holistic approach to health determinants acts as a additional barrier to health for First Nations Peoples. This discrepancy between the philosophy of Western medical care and health as defined by First Nations communities has contributed to a widening of the gap in health disparities for Indigenous peoples, demonstrated by rising mortality and morbidity within First Nations populations.

Violence is not often recognized as a major health issue within Western medicine, despite the fact that violence is the leading cause of death worldwide for people between 15 to 44 years, accounting for $14 \%$ of male and $7 \%$ of female deaths globally (World Health Organization, 2002).

The World Health Organization's landmark report, 2002 World Report on Violence and Health (2002), addresses health issues related to various acts of violence at personal and community levels globally. Epidemiological, sociological, forensic, and health care statistics provide evidence identifying violence as a leading cause of mortality and morbidity globally in Indigenous populations (Centers for Disease Control and 
Prevention, 2003; Health Canada, 2006; A. Smith, 2005). There is little information, however, regarding the connections between the current health care systems which regulate the provision of services to First Nations communities affected by violence, and their perspectives regarding violence, health, community, and healing beliefs (Assembly of First Nations, 2006b).

\section{First Nations Epistemology and Conceptual Framework}

\section{Traditional roles of Elders in First Nations communities}

Elders are the traditional keepers of knowledge in many societies, including the First Nations of Canada. Over the past hundred years, the traditional health of individuals, families and communities has been disrupted as colonization and residential schools usurped the role of the First Nations Elder. First Nations children, the very heart of the culture, were removed from the communities and transported to residential schools where they were forced to assimilate Western cultural elements of language, religion, and traditions. First Nations traditional ceremonies were outlawed within communities and Traditional roles were not acknowledged by the Canadian government. The resulting legacy of the historical trauma was the loss of intergenerational connection within the culture (D. Smith, Varcoe, \& Edwards, 2005).

Elders continue to be respected within First Nations as sources of wisdom and their lives represent the values of the culture. Transmission of the cultural values is inherent to the wisdom, which is carried in the language by the Elders (L. Smith, 2007).

Leroy Little Bear, a Blackfoot scholar speaking at a research agenda of the Royal Commission on Aboriginal Peoples, described the combination of Aboriginal philosophy and Western scientific theory as "jagged worldwide views colliding" (Castellano, 2004, p. 103). Little Bear exemplifies the importance of understanding various viewpoints, and acknowledging the inherent differences and contradictions of the Western perspective as compared to a First Nations' epistemological perspective. The historical process of European scientific thought and research has traditionally described violence with a relative absence of understanding of its significance within the First Nations culture (Little Bear, 2000).

Social, political, and economic determinants of health external to Aboriginal communities have not been integrated into research in the past, and often Aboriginal communities have been portrayed as the problem, without sufficient resources to solve the problem (L. Smith, 2007). Marie Battiste (2000) describes the work that is required for healing and restoration of Aboriginal cultural heritage as including the reconnection of language, restoration of Aboriginal ecology, and the connection between Eurocentric and Aboriginal knowledge. 


\section{The spiritual nature of Aboriginal research}

Prior Aboriginal research provides direction and support for practitioners, communities, and policy makers regarding the use of a strength-based approach including oral tradition for Elder care issues. A positive aspect of oral tradition is its ability to recreate situations for those people who have not experienced them, so that others can be educated through this Indigenous tradition (Crukshank, 1990). Using an emic approach to describe views allows understanding of Elders' traditional cultures and language as well as any associations between intergenerational relationships and violence (Posey, 2004).

Based on the prior work regarding cultural humility by Tervalon, and MurrayGarcia (1998) and Salois, Holkup, Tripp-Reimer, and Weiner (2006) identified two major constructs in their work which are inherent to the success of cultural research. These constructs are viewing research in the form of a spiritual covenant and the role of cultural humility. The responsibility of respecting and protecting Sacred Knowledge and the relationship to subsequent policy formulation and implementation are important aspects of the spiritual nature of research. The research and resulting program development and implementation with community becomes a covenant with reciprocal responsibilities and obligations. The principle of reciprocity guiding research and subsequent program policy acts to balance and maintain sustainability, in regard to identified need, resources, and outcomes. The concept of lateral transfer of culturally relevant knowledge and practices between communities as a component of healing is reinforced by current First Nations research. The principle of harmony which consists of valuing differing opinions and using consensual decision making within the communities, allows for respectful input and consideration of health policy proposals while ensuring that health policy is guided internally from a cultural context with facilitation of the entire community. The concept of cultural humility is a commitment to non-paternalistic partnerships and ongoing selfcritique and evaluation while strengthening the development of multi-cultural relationships (Christopher, Watts, McCormick, \& Young, 2008; Salois, et al., 2006).

First Nations epistemology is centered within the spirit, which runs through life. Oral traditions are a way to express understanding and balance with self and others. Oral stories and prayers are also a way to connect with ancestors and culture. Indigenous ways of knowledge are circular in nature, encompassing mental, emotional, physical and spiritual ways of being. This research journey for contextual meanings of relationships and violence is considered a knowledge quest, and as such must follow appropriate cultural protocols within the First Nations communities regarding knowledge quests and the protection and sharing of knowledge (Canadian Institutes of Health Research, 2007; Salois, et al., 2006; L. Smith, 2007; Umeda, 2002).

Chandler and Lalonde (2004) and McCormick (1994) and other First Nations researchers working with health conditions of alcohol and violence through a First Nations perspective, emphasize the importance of the use of a self-determination model integrating traditional knowledge and Elder's wisdom in research and program development. These factors along with community organization factors were found to facilitate decreases in youth suicide rates while providing baseline outcome criteria for 
community program development, policy and funding parameters. Community-based judicial and legal programs can also be designed to integrate traditional community and family roles, which facilitate respect, safety, and accountability for the welfare of elders within communities. These programs also provide a voice for the traditions and wisdom of the Elders and the First Nations peoples. A strength-based program model as described above provides a promising framework for the study of violence within First Nations communities.

Acknowledgement, identification, and definition of health conditions such as violence which affect First Nations communities are necessary to allow prioritization of programs and allocation of resources; though it is extremely important to avoid incorrect assumptions which associate or equate a health problem being studied, with the culture. A focus on the complexities and nuances of culture including the resiliency, strength, integration, and cultural renewal of First Nations health provides insider perspectives and acts to decrease the insensitivity of Western perspectives (Kirmayer \& Walaskakis, 2009).

In the post-colonial period, there has been a shift toward creation of a dialogue between researchers and Aboriginal communities. The creation of a dialogue acts to create a culturally safe, inclusionary environment. This research seeks to understand the views of First Nations Elders in regard to relationships. As individuals act based on their views, it follows that a cultural awareness of these views will be helpful in the identification, treatment and prevention of violence in First Nations communities. Hearing the views through the sharing of stories in the language of the Elders allows the observation of similarities regarding beliefs, attitudes and values through the stories (Bennett, 1998). 


\section{CHAPTER 2. REVIEW OF LITERATURE}

\section{Northern British Columbia and Canada}

The province of British Columbia (BC) is located in the southwest corner of Canada, and ranks fifth in size of Canadian provinces with a total area of 944,735 square kilometers (364,764 square miles). In 2005, the total population within the province was $4,141,272$, and the Aboriginal population was 151,783, comprising $3.7 \%$ of the provincial population. Thirty-five percent of the total First Nations population of British Columbia resides in Northern BC, which includes more than 16 Traditional First Nations Bands, in addition to other Aboriginal, Métis, and Inuit groups who reside in Northern BC (Northern Health, 2005).

Eight First Nations Bands in Northern British Columbia form the Carrier Sekani Tribal Council (CSTC) Association, with over 10,000 members. The members include the Ts'il Kaz Koh First Nations (Burns Lake Band), Nak'azdli Band, Nadleh Whut'en, Saik'uz First Nation, Stellat'en First Nation, Takla Lake First Nation, Tl'azt'en Nation, and Wet'suwet'en First Nation. The Carrier Sekani territories consists of 78,700 $\mathrm{km}^{2}$ and extend west from the Coast Mountains, north to the Mineca Mountains, east to the Rocky Mountains and south to the Quesnel, Blackwater and Dean rivers (Brown, 2002).

\section{Carrier Sekani Tribal Council and Carrier Sekani Family Services}

A critical analysis regarding the current issues surrounding Aboriginal health supports the importance of understanding the cultural concepts, values, and assumptions that shape Indigenous peoples. The work of outside anthropologists in the past has been used to generalize about Aboriginal people from the dominant culture's views; often describing practices and making assertions without gaining the perspectives of the communities being studied (Kuwayama, 2004).

The following Carrier and Sekani Declaration of Alliance of 1982, is reflective of the Carrier Sekani Tribal Council's philosophical perspectives:

Recognizing that we Yinka whet'enne have a common ancestry, language, land, way of life and Bahl'ats system; Acknowledging that our ancestors saw it wise to organize and conduct our personal, family, cultural, political and legal relationships through our Bahl'ats system. We, Yinka whet'enne, put our hearts and minds together and for the future of our people say:

- We acknowledge Yoodughi, The Creator.

- We remember our Ancestors and acknowledge their love for us.

- We see the faces of the generations of our people not yet born and we pass our love to them. 
- We respect and love our Land and know that, as our Mother, it has provided for us: and according to our Teachings we will stand as one to respect and protect our Land and all life on it.

- $\quad$ Our elders and young are important, for the elders hold the knowledge of our people's past and the young hold our hope for the future; we will work together to teach our young about Yoodughi, our Land, Languages, Teachings, and our Bahl'ats so that they will pass it on to their children and to future generations.

- $\quad$ Our Bahl'ats system is sacred to us; in it we stand as one in times of great loss and in times of great celebration.

- We will carry our ways and our business with respect, care and love for each other and we will create stability and confidence in ourselves and our young to ensure our people and our ways will survive in the future.

- Where we have differences we will talk to each other with great respect, care and love and work out our differences to ensure harmony and balance in our own life, families and communities.

- $\quad$ And as long as the sun shines and our rivers flow we will stand with each other, support each other and do all we can to lift up each other's heart and spirit.

- With this we welcome the newcomers to our Land and we will share with them our Vision of who we are and knowledge about our Land; and we will live with them in a spirit of friendship and harmony.

- We agree that the Leaders of our people will carry out talks in our Bahl'ats system with the newcomer's governments as a means of negotiating a fair, just and lasting agreement about our Land. (Carrier Sekani Tribal Council, 2007, pp. 4-5).

The Carrier Sekani philosophy is described by its members as "coming from the land" (Carrier Sekani Tribal Council, 2007, p. 5). The interdependent relationship of community and land guides the lifestyle and land use of these First Nations peoples. The land is considered a family member, whose teachings regarding its use pass through intergenerational relationships. As Rita George, a Wet'suwet'en First Nations Elder states, "The only way to manage the land is to really listen to the Elders, and to really conduct themselves under our law, our Wet'suwet'en Law, our ancestors Law" (Carrier Sekani Tribal Council, 2007, p. 11). All life forms are considered sacred and interconnected within the Carrier Sekani community. Pre-colonial, traditional community practices and stories emphasized interrelationships with the land and mutual respect, humor, generosity, and patience (Brown, 2002).For the community to heal from colonial and post-colonial dislocation, the Carrier Sekani have identified that families need to be 
rebuilt, language needs to be restored, and an economic and political base needs to be reconstructed to allow control of resources and territory.

Carrier Sekani Family Services (CSFS) was developed to reestablish First Nations control in areas of community values and teachings, and continues to be committed to the healing and empowerment of First Nations People within Carrier and Sekani Territory under the guidance of their Elders (Carrier Sekani Tribal Council, 2010). CSFS with the Carrier Sekani Tribal Council has developed a comprehensive infrastructure for social, health, and legal problems. The long-term goal is provision of social, health, and legal services, consistent with the Council's objective of self-governance. Eleven First Nations communities comprise CSFS membership, including; Ts'il Kaz Koh (Burns Lake Band), Cheslatta Carrier Nation, Nadleh Whut'en, NeeTahi Buhn Band, Saik'uz First Nation, Skin Tyee Band, Stellat'en First Nation, Takla Lake Band, Wet'suwet'en First Nation, Yekooche First Nation, Lake Babine Nation.

Under its Certificate of Incorporation, the five objectives of the Carrier Sekani Family Services Society are stated as the following:

1. To develop and deliver health, social, family corrections and legal services in accordance with the needs, socio-economic conditions, and values and beliefs of the Carrier Sekani Nations.

2. To deliver all services in accordance with our great law of sharing wealth as set in our Balhats (potlatch) system.

3. To develop, implement and enhance Carrier and Sekani Human Services philosophies and standards of native people residing in the Carrier Sekani traditional territory.

4. To encourage and initiate activities appropriate to the strengthening and unifying of human service personnel in the Carrier Sekani traditional territory.

5. To develop and deliver training programs for the advancement and accreditation of human service workers in Carrier Sekani territory in accordance with Carrier Sekani philosophy and standards.

\section{Disruption of First Nations Ways of Life, Historical Trauma and Violence}

Historically, the arrival of Europeans adversely affected the First Nations culture on many levels. Initially epidemics raged through Indigenous communities caused by illness brought by the explorers and settlers. Colonization also created a scarcity of Indigenous Traditional foods and a loss of Traditional economies through mass destruction of natural resources. Indigenous peoples' Traditional lands were seized by the Canadian government and Indigenous communities were forcibly relocated onto small tracts of land in overcrowded living conditions with poor sanitation. All of these effects 
of colonization caused illness and mass deaths of Indigenous peoples. The original Indigenous population within the British Columbia region in the 1700's was estimated to be 250,000 , but decreased post-contact to 23,000 in the 1920's due to the effects of colonization (Battistte, 2000; Office of the Provincial Officer of British Columbia, 2009).

Laws were enacted in Canada that prohibited any Indigenous cultural practices or ceremonies, with the goal of assimilation of First Nations into the newly dominant European culture. Part of the government assimilation process with the First Nations peoples was the removal of all British Columbia First Nations children, ages 5 to 17 from their families and communities, with placement into regional residential schools as mandated by Canadian law. The taking of children from their families and communities continued for over a hundred years, from 1863 to 1984, when the last residential school closed. It is estimated that there are over 35, 000 Residential School survivors in British Columbia who experienced long-term physical, verbal, and sexual abuse in these schools (Akhtar, 2010; McDonald, 2007; Truth and Reconciliation Commission of Canada, 2012).

Robert Yazzie (2000), writing in Reclaiming Indigenous Voice and Vision, described the effects of power and domination on Aboriginal peoples within the colonization process in North America. Yazzie relates the introduction of a hierarchal system in which a man was deemed to be superior to a woman and allowed to dominate her, as creating a framework for interpersonal violence. The legal and judicial systems then created laws and legislated consequences for violent behavior. This is in stark contrast to traditional Aboriginal social structures of equality and consensus in which peacekeeping and healing of family and communities required personal responsibility, respect, and "right relationships" (Yazzie, 2000, p. 46). Yazzie contends that the current system of courts and prisons only continues the legacy of domination and triangulation of power without requiring individuals or members of the community who are affected by the violence to deal with the inherent conflict.

Historical trauma and associated illnesses within First Nations communities have been well documented as part of the legacy of colonization. The process of colonization included the forced relocation of communities, loss of Traditional lands containing medicinal plants and the creation of laws which prevented the practice of Indigenous culture, including Traditional methods of healing. Post-colonization effects of this disruption of Traditional lifestyle included the introduction of chronic disease, violence, and drugs and alcohol into Indigenous communities (Assembly of First Nations, 2006a; Battistte, 2000; D. Smith, et al., 2005; Villegas, Neugegauer, \& Venegas, 2008).

There has existed a historical precedent of Western society and medicine's lack of acceptance of First Nations traditional methods of healing as unscientific or lacking in evidence-based framework (Assembly of First Nations, 2006a; Battistte, 2000; Chandler \& Lalonde, 2004; McCormick, 1994; L. Smith, 2007; Villegas, et al., 2008). Western scientific approaches have historically been deemed superior, despite the lack of success with associated programs and continued high rates of mortality and morbidity in First 
Nations population related to injury, alcohol use, and interpersonal violence (Health Canada, 2005; Kirmayer \& Walaskakis, 2009; McCormick, 1994).

Recognition of the historical trauma associated with oppression is an important component of healing with individual and community health (Assembly of First Nations, 2006a; Battistte, 2000; Etienne \& Leacock, 1980; D. Smith, et al., 2005; L. Smith, 2007). The Truth and Reconciliation Commission of Canada (TRC) was recently formed with the goals of investigating residential school abuse, and fostering healing and reconciliation through its activities within a five year timeline. The TRC was given the mandate of gathering statements from residential school survivors, hosting transCanadian events, and documenting the residential school experience (Truth and Reconciliation Commission of Canada, 2012).

\section{Traditional First Nations Roles}

McCormick (1994), in his dissertation research with First Nations healing, elicited factors which facilitate healing for First Nations people. McCormick's research described the importance of 14 categories of healing factors within the First Nations people. These categories included participating in ceremony, expressing emotion, learning from a role model, establishing a connection with nature, exercising, being involved in challenging activities, establishing a spiritual connection, obtaining healing/support from others, engaging in self-care, setting goals, anchoring self in tradition and helping others. (McCormick, 1994, p. 134).

McCormick's work supports the view that effective healing for First Nations people must have a focus on "interconnectedness" rather than personal autonomy. The connections between individual, family, community, culture, and spirituality, and nature are integral to the healing process of First Nations people. These findings also have clinical implications for First Nations communities who can facilitate healing from injury and abuse through traditional First Nations beliefs systems, and the use of various traditional healing methods. These findings reinforce the abundance of healing resources inherent to the First Nations communities and provide information regarding the importance and incorporation of factors which facilitate healing such as ceremonies, inclusion of nature into community, and integration of the caregiver role of Elders and families within community programs. The implementation of a strength-based model of care allows for recognition of the importance of community in the healing process, as well as the role of the Elder and interconnectedness with community health. Identified healing factors, including preservation of oral traditions and reawakening of cultural identity of the community, act to facilitate the role of the Elder in the First Nations culture as keeper of knowledge, and supports the importance of the Elder's role in bridging the past, present, and future (Crocker, 2005). 


\section{Indigenous Health Disparities Related to Intentional and Unintentional Injury}

Health Canada (1996) has identified injuries, both intentional and unintentional, as leading causes of mortality and morbidity within Aboriginal populations nationwide. Unintentional injuries commonly referred to as accidents, are injuries that occur without the intention of harm to self or others. Intentional injuries are those inflected to self or others in an intentional manner, such as suicide, homicide, physical or sexual abuse. Injuries account for a disproportionate level of mortality within the Aboriginal population as compared to the general population of Canada. Injuries remain the leading cause of death within Aboriginal peoples under the age of 45, and First Nations peoples have a $6.5 \%$ increased risk of dying due to injury over the average Canadian. In British Columbia (B.C.), 28 percent of all First Nations deaths during 1993 were due to injuries, as compared to 7.6 percent of the general British Columbia population. (Health Canada, 2001). Figure 2-1 describes the high age-standardized injury death rate in 1997 for British Columbia First Nations as compared to the general Canadian population and First Nations populations residing in various providences (Health Canada, 2001).

Previous studies in Canada and the United States have documented high rates of violence and victimization in North American First Nations and Native American populations (Assembly of First Nations, 2006a; Centers for Disease Control and Prevention, 2003; Health Canada, 2006; Yuan, Koss, Polacca, \& Goldman, 2006). Injuries among First Nations peoples are multifaceted in etiology and related to interactions among the various determinants of health. Suicide rates in Aboriginal peoples are some of the highest in the world, and account for one quarter of all First Nations deaths attributable to injury. From 1991-1993, the suicide rate for First Nations youth, 5-14 increased by 45 percent as noted in Figure 2-2 (Assembly of First Nations, 2006c; Chandler \& Lalonde, 2004; Health Canada, 2001).

Chandler and Lalonde (2004) have studied suicide in Indigenous youth and found social correlates at the regional, band, and community level. Their research demonstrated that First Nations communities with intact or healthy cultures, preservation of their cultural history, and self-government control over Traditional lands, health, education, child protection and functioning local jural systems have an absence of youth suicide. This is in severe contrast to those First Nations communities that lack the above selfdetermination factors, which have youth suicide rates greater than 150 times the Canadian average rate of 6.7 per 100,000 (Chandler \& Lalonde, 2004; Public Health Agency of Canada, 1999). According to Yuan, Koss, Polacca and Goodman (2006); intact cultural identity and enculturation, including Traditional spiritual and health practices, have a protective effect from violence-related incidents.

The high rates of mortality and morbidity associated with all injuries within Aboriginal communities are reflective of the ongoing health disparities between the general Canadian and Aboriginal populations. Colonization has resulted in racism, poverty, and lack of self-determination in many Indigenous communities. Poverty, overcrowding on reserves, sub-standard housing and lack of the basic amenities of living including safe water, are associated with high rates of injuries, including fire-related deaths. Fire related deaths and hospitalizations in First Nations peoples are 6-18 times 


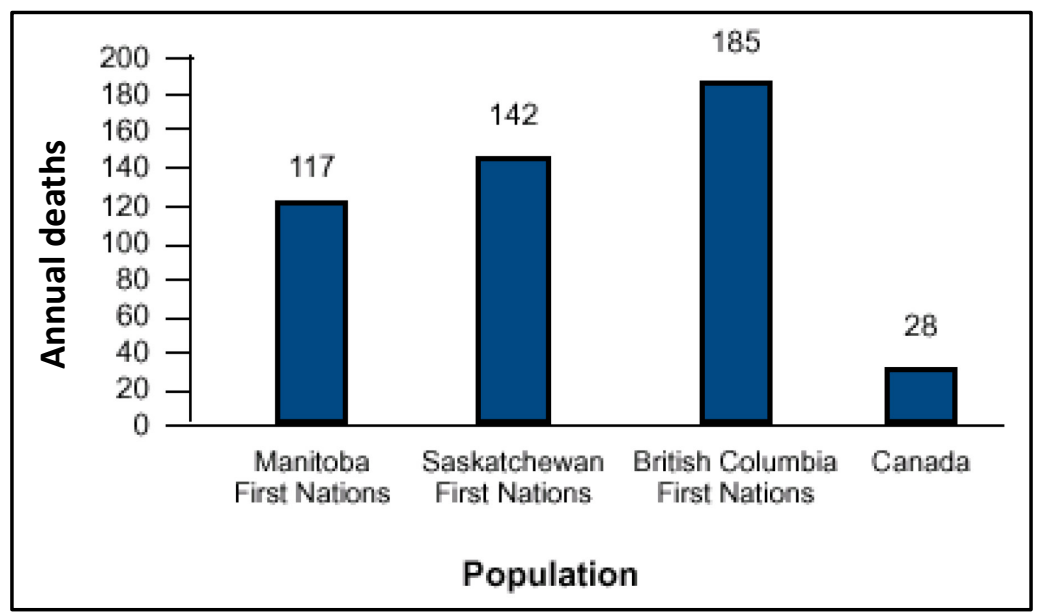

Figure 2-1. Age-standardized injury death rate for selected provinces, 1996-1997.

Source: Adapted from Health Canada (2001). Unintentional and intentional injury profile for Aboriginal people in Canada. Retrieved. November 7, 2011 from http://www.hcsc.gc.ca/fniah-spnia/pubs/promotion/ injury-bless/2001 trauma/index-eng.php\#figure5 


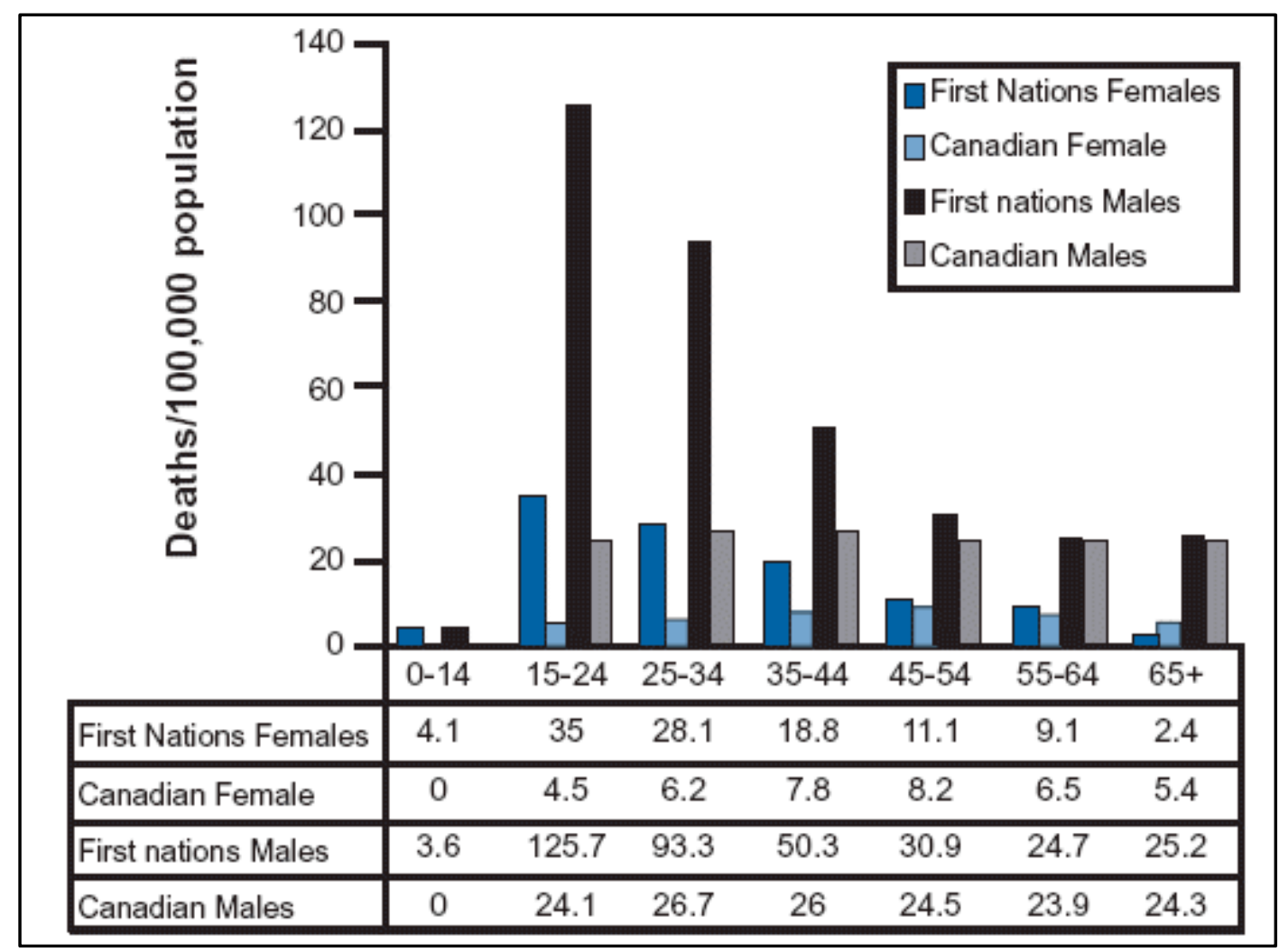

Figure 2-2. Crude suicide death rate by age group for First Nations and Canadian population, 1989-1993.

Source: Adapted from Health Canada. (1996). First Nations, Inuit and Aboriginal Health. Retrieved November 7, 2011 from http://www.hc-sc.gc.ca/fniahspnia/pubs/promotion/_injury-bless/2001 trauma/index-eng.php\#figure10 
higher than the general population in Canada according to 2006 statistics. In British Columbia, from 1991 to 1998 , the age standardized mortality rate from fire was 0.8 in First Nations communities versus 0.1 for general British Columbia population (British Columbia Vital Statistics Agency, 2004). The lack of governmental control granted to Aboriginal communities regarding public health issues has been identified as a barrier to the development of culturally appropriate community centered programs directed toward injury mortality and morbidity reduction (Assembly of First Nations, 2006c). Figure 2-3 describes the external causes of death for the First Nations population of British Columbia from 1991 to 1998.

\section{Violence against Aboriginal Women}

In 2002, the BC Women's Violence Again Women Provincial Health Initiative Advisory Committee held a two-day forum, "Strategizing for Safer Communities for BC Aboriginal Women," to identify and respond to violence against Aboriginal women in British Columbia. The forum focused on violence against Aboriginal women; as these women experience the highest rate of violence of any group in Canada as evidenced by both qualitative and quantitative data (Native Women's Association of Canada, 2010; Pacific Association of First Nations Women, BC Women's Hospital and Health Center, BC Association of Specialized Victim Assistance and Counseling Programs, 2003).

Violence-related concerns regarding Aboriginal women in British Columbia identified at the $2002 \mathrm{BC}$ two-day forum included health disparities of extremely high levels of violence against Aboriginal women, lack of services to deal with violence, gaps in provision of available services, and inadequate response to the high levels of violence within communities. Aboriginal women at the forum also identified the absence of provincial representation for Aboriginal women's issues and restrictive funding to violence-prevention programs, social and health services, and domestic violence programs. The forum acted to reinforce that the violence Aboriginal women experience is the resulting legacy of violence secondary to colonization; residential schools; and systemic racism, sexism, and poverty. When queried about preventive and treatment services for violence again Indigenous women, Aboriginal women stated clearly that women's healing is connected to the healing of men, children and Aboriginal communities (Pacific Association of First Nations Women, 2003).

The 1989 rates of violence against Aboriginal women in Canada were estimated by the Ontario Native Women's Association to affect $80 \%$ of all Aboriginal women. The rate of spousal homicide for Aboriginal women in 2004 was reported by Statistics Canada (2006) to be eight times that of non-Aboriginal women (Figure 2-4). Canadian rates of stalking experienced by Aboriginal women and non-Aboriginal women in 2004 as reported by Health Canada (2006) were $21 \%$ and $11 \%$ respectively. 


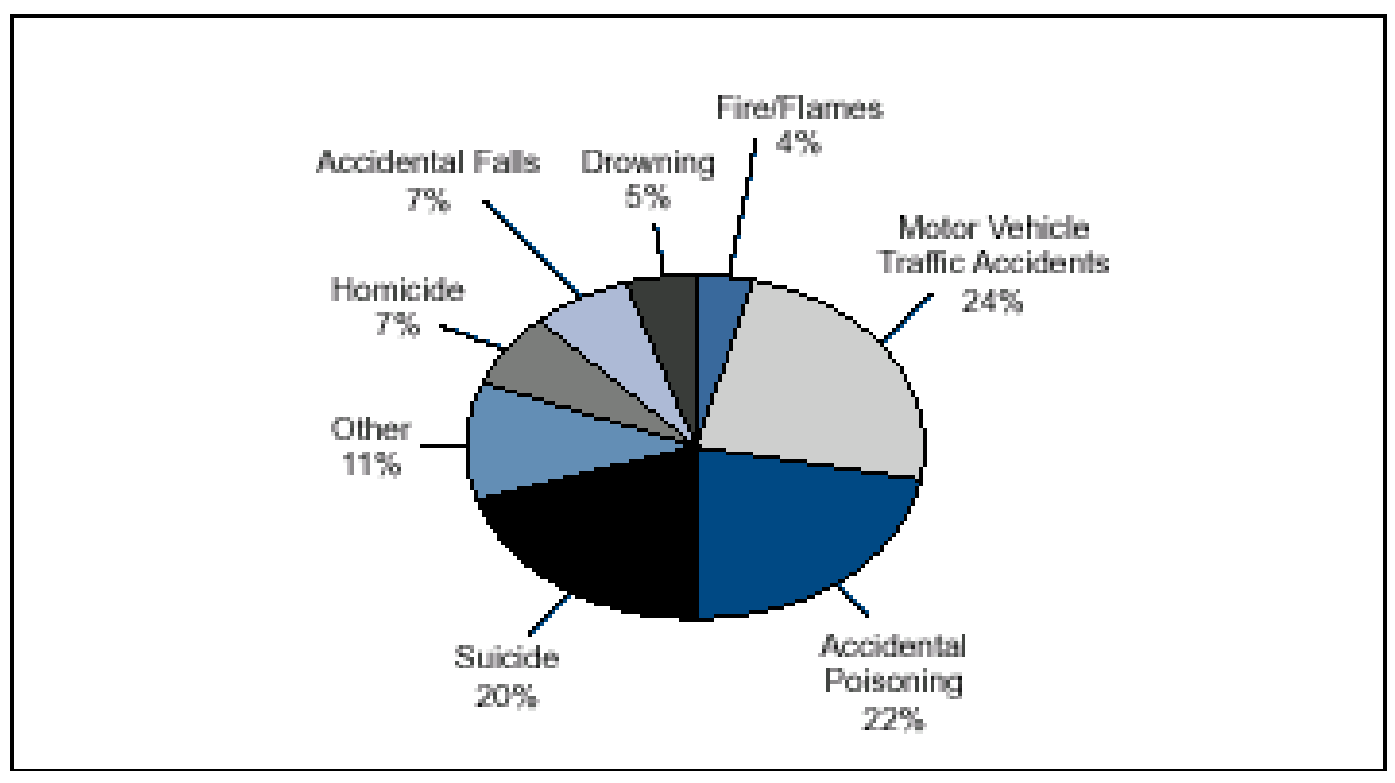

Figure 2-3. External causes of death: B.C. status Indian population, 1991-1998.

Source: Adapted from Health Canada. (2001). Unintentional and intentional injury profile for Aboriginal people in Canada. Retrieved November 7, 2011. Retrieved from http://www.hc-sc.gc.ca/fniah-spnia/pubs/promotion/ injury-bless/2001 trauma/indexeng.php\#figure9 


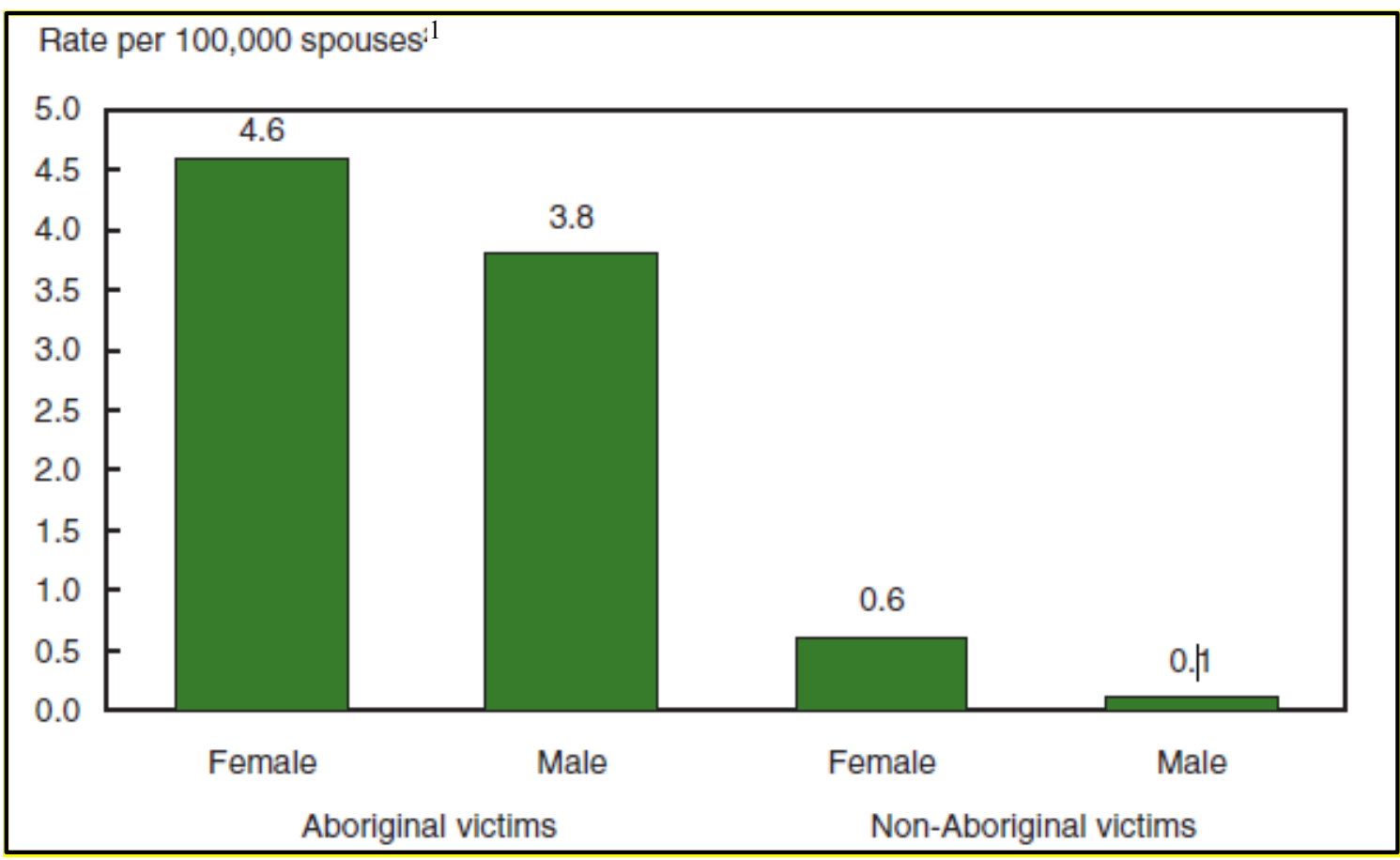

Figure 2-4. Rates of spousal homicide, by sex of victim and Aboriginal status, 1997 to $2000^{2}$.

${ }^{1}$ Rates are calculated per 100,000 spouses (legally married, separated, divorced and common-law men and women 15 years of age and over) of self-identified Aboriginal origin (North American Indian, Métis or Inuit). Population estimates were derived from 2001 post-census estimates and 1996 Census counts, provided at July 1st by Statistics Canada, Census and Demographic Statistics, Demography Division.

${ }^{2}$ These data exclude those victims where police-reported Aboriginal status was unknown or not collected. In accordance with internal guidelines, some police services (e.g., RCMP and Toronto Police Service) do not report the Aboriginal status of victims and accused persons to the Homicide Survey. This analysis excludes 32 victims whose Aboriginal/non-Aboriginal status was unknown, undisclosed or not collected between 1997 and 2000. For data prior to 1997, it is not possible to separate 'non-Aboriginal' status from 'not collected'.

Source: Adapted from Statistics Canada. (2006). Measuring Violence Against Women: Statistical Trends 2006 (p. 67). Retrieved from http://www.unece.org/fileadmin/DAM/stats/gender/vaw/surveys/Canada/2006 Publication_VAW.pdf 


\section{Violence against Elders}

Health care professionals are responsible for the assessment and treatment of health care problems in the aging population. These professionals ideally are in a position to identify abuse and neglect of older individuals, but current research on elder abuse has reported a lack of identification and intervention of abuse in the elderly by health care professionals. Abuse of elders occurs on many levels, and may be subtle, increasing the difficulty in both elder and health care provider recognition (Burgess, Dowdell, \& Brown, 2000; Carney, Kahan, \& Paris, 2003; Krueger \& Patterson, 1997; Saveman, Hallberg, \& Norberg, 1992; Tietelman \& Copolilio, 2002).

The prevalence of abuse in elders residing in Northern British Columbia is not known (British Columbia Injury Research and Prevention Unit, 2007; Health Canada, 1994). Data on the prevalence of elder abuse varies between states and provinces in North America due to the differences in provincial and state statutory guidelines regarding investigation and reporting of abuse, and types of health data and sources. Despite the lack of epidemiological studies, a marked increase in elder abuse was reported from 1986 to 1996 in the United States and Canada (Canadian Task Force on the Periodic Health Examination, 1994; Health Canada, 1994; National Center for Injury Prevention and Control, 2001; National Center on Elder Abuse, 1999).

The lack of consensus among health care professionals as to what constitutes elder abuse adds to problems with identification of elder abuse. Laws and definitions of elder abuse vary globally, and within states and provinces in the United States and Canada. Cultural definitions of abuse vary, as do definitions of what constitutes abuse within various health care groups (Wong \& Marr, 2002).

An accurate estimate of elder abuse in First Nations communities in Northern British Columbia is hampered by the lack of a shared definition of abuse, lack of recognition, and subsequent lack of reporting of abuse for this group (British Columbia Injury Research and Prevention Unit, 2007). The problem of elder abuse is made worse by secrecy within family structures and communities, interfering with accurate reporting, causing a probable underestimation of cases (British Columbia Injury Research and Prevention Unit, 2007; Fisher \& Dyer, 2003; Health Canada, 1994; Kahan \& Paris, 2003; National Center on Elder Abuse, 1999). 


\section{CHAPTER 3. METHODOLOGY}

\section{Introduction}

The goal of this research was to understand the Elders' point of view and reality. A respectful and mindful approach to First Nations Elders' views regarding health, violence and relationships is consistent with cultural humility, a guiding principle of multicultural research (Salois, et al., 2006; Umeda, 2002). Past research was often not collaborative with First Nations peoples and was framed in non-Indigenous understandings, which were misguided. Past research acted to create harmful stereotypes and policies, which have inaccurately reflected First Nations perspectives (Canadian Institutes of Health Research, 2007; Castellano, 2004; A. Smith, 2005). An advantage of the use of methodology such as the community based participatory action research approach is the ability to focus on the reporting of alternative realities and way of thinking within the larger First Nation community. Discovering what is culturally grounded in regard to beliefs and practice provides a framework for subsequent work.

\section{Community Based Participatory Research Methodology}

Research literature is rich in material that speaks to the importance of establishing trust within the relationship between researcher and community with which he or she is working (Battistte, 2000; Castellano, 2004; Chandler \& Lalonde, 2004; Holkup, TrippReimer, Salois, \& Weinert, 2004; McCormick, 1994; L. Smith, 2007; Umeda, 2002; Wilson, 2008). Indigenous communities have had a long history of being subjected to outside researchers exploiting information, resources, and knowledge, with lack of control over the process of research or use of information sharing without residual benefit to the community (Castellano, 2004; Christopher, et al., 2008; Holkup, et al., 2004; L. Smith, 2007). Many times, communities are not informed of the findings of research and have no role in the process of dissemination of findings, or the ability to confirm the legitimacy of the findings. Community-based participatory research is a method that builds trust between the researcher and community in which goals, process, analysis and implementation of research are directed by the community in partnership with the researcher. Communities work jointly with the researcher to identify issues to be studied and the process used, as well as analysis and implications and dissemination of results.

Christopher et al. (2008) identified levels of trust building within communitybased participatory research partnerships which provided a foundation to accomplish my research. The first level of building trust was the acknowledgment of my personal background and dissertation process at the University of Tennessee Health Science Center. The second level of trust pertained to establishing trust within the community and partnerships. I accomplished trust building by reviewing the project's goals, research process, and obtaining mutual agreement with expectations regarding the process and outcomes, without privileging my voice or dialogue over those of First Nations Elders. This dialogue began with initial contact with the Carrier Sekani Family Services and has continued beyond the writing of the analysis of data. 
First Nations members have Aboriginal and treaty rights which at least theoretically include self-governance, independent jurisdiction, authority, and control of public health and health data (Assembly of First Nations, 2006b). According to the principles of Ownership, Control, Access and Possession (OCAP), under the First Nations principle of self-determination; First Nations communities have the right to control all aspects of research and collection of information. These principles guided the priorities and capacities of all parties involved in this research project.

\section{Design and Setting}

This study used a community-based participatory research design to explore social and cultural context through the views of Carrier Sekani Elders. The communitybased participatory design is reflective of the Indigenous axiology of relational accountability within Indigenous research methodology, as described by Shawn Wilson (2008). This design also added to the validity and reliability of the research project due to the community's role in ensuring the accuracy of the cultural context and relationality of the research process. This design incorporated interviews with First Nations Elders and their communities who were partner researchers and who collaboratively decided which information was to be sought in interviews, what type of interview process was utilized, and how the results were to be interpreted and utilized.

The community-based participatory research design acted to support the aims of the study which were: To explore how First Nations Elders understand violence in their communities, To explore what First Nations Elders believe gives rise to violence in First Nations communities, To illuminate the factors that First Nations Elder view as affecting the safety and well-being of Elders living in First Nations communities, To explore First Nations Elders' narration of intergenerational relationships before and after contact, and To make clear factors which First Nations Elders view as required for Elders to remain safe and stay within their respective communities.

Initial conversations first occurred with members of the Carrier Sekani Tribal Council (CSTC) and the Carrier Sekani Family Services (CSFS) Research Director who indicated that this was a project in which they were interested in participating. I first sought CSFS approval of this proposal following cultural protocol, reviewing the questions which I wanted to ask Elders. After the initial verbal approval, I received full written approval post-review of my proposal from the CSFS Research Committee. The next stage of this project design was to gain formal approval from my dissertation committee and from the Institutional Review Board (IRB) at the University of Tennessee Health Science Center (Appendix A) so as to proceed with this research study. I also received full approval from the University of Northern British Columbia's Research Ethics Board (Appendix B) as required by the University of Tennessee IRB. Upon receiving all formal approval, I then presented my research design and methodology to the CSFS Research Committee to identify individual Band Councils and Communities, and discuss culturally contextual design modifications and community partnerships for this project. Qualitative interviews utilized open-ended questions to facilitate cultural context of the issues discussed. A draft guide for questions (Appendix C) was 
formulated with initial input from a member of the Carrier Sekani Tribal Council and received further input from the Elders after approval was granted from the Research Committee of the Carrier Sekani Family Services, University of Tennessee Health Science Center IRB, and the University of Northern British Columbia Research Ethics Board. Only two of the six interviews were recorded due to the requests of some of the Elders interviewed to have a conversation without the use of formalized questions or recordings.

\section{Elders to Be Interviewed}

Interviews were initially planned in the Northern British Columbia communities of Saik'uz, Stellat'en, and Ts'il Kaz Koh (Burns Lake) First Nations, pending community approval. These communities were to form a preliminary stage of research which would continue within all of the member communities of the Carrier Sekani Family Services (CSFS). Consultation with Elders and the CSFS/Band Council members provided initial direction regarding the setting of the study. It was hoped that individual communities would agree to the interviews of Elders occurring in their homes or community centers, including members living off reserve. The setting chosen was to be culturally respectful and follow the Ts'il Kaz Koh community's protocols.

Elder participants were sought in a purposeful manner from the population of First Nations Elders of the Carrier Sekani Family Services member communities residing in Northern British Columbia. Elders were selected from initial meetings with Carrier Sekani Family Services and Tribal Councils, and also recruited utilizing snowball sampling within the Ts'il Kaz Koh community. Elders were interviewed solely from the Ts'il Kaz Koh (Burns Lake) First Nations community, as the Saik'uz and the Stellat'en communities both decided not to participate in the research. The Cheslatta Nation's Chief and Council gave initial approval to participate, but upon returning to Northern B.C. to meet with the Cheslatta Elders, the newly appointed Cheslatta Chief and Council did not approve the research. I decided that the interviews from the Ts'il Kaz Koh (Burns Lake) Elders would constitute a study used for my dissertation and to form the basis for further study within the Carrier Sekani communities. Participants were paid $\$ 50.00$ as recognition of their effort and to compensate for their time, and were also given a gift as a means of thanks and recognition of their contributions.

\section{Researcher's Role}

Research methodologies required following First Nations traditional protocols and processes in knowledge seeking. Honoring and respecting the community, Elders, and Traditional knowledge holders was an integral part of seeking Elders' views.

Establishing a relationship with the Northern British Columbia First Nations community required establishing trust, with assurances that I would be compliant with ethical obligations and that our relationship would continue as one of reciprocity. Individual views and beliefs were sought as part of the research process and then reflected back to 
the Elders to confirm understanding and subsequently to the Carrier Sekani community for further validation (Castellano, 2004; Salois, et al., 2006).

Holkup et al. (2004) described the use of criteria which can be used to ensure stakeholder authenticity and rigor with qualitative research. These criteria include: Fairness, in which differing views and perceptions are honored; Ontological authenticity, which refers to the degree of change within perception during the research project; Educative authenticity, in which perceptions are modified due to the research process; Catalytic authenticity in which action is facilitated; and Tactical authenticity in which stakeholders are empowered. These criteria are complimentary to the Royal Commission on Aboriginal Peoples guidelines for Aboriginal research (2006), which strive to move Aboriginal research beyond the status of stakeholder for participants by specifying that Aboriginal communities be considered full partners in research (Castellano, 2004).

Credibility has been noted as a research criterion, which increases the validity of the qualitative research process. As I am not a member of the First Nations community, my credibility was strengthened within the study through increasing the frequency of my visits, extending the time that I was within the community, and through the use of collaborative review of interpretations with participants, community, and colleagues (Castellano, 2004; Holkup, et al., 2004; Patton, 2002). Mindful inclusion of the above criteria helped me to strengthen this qualitative research project. Individuals and community participants validated the accuracy of the contextual meaning of health and violence through the component of community participatory action. First Nations community involvement provided a consistent voice which identified problems, development of interventions, data collection, and analysis and dissemination.

\section{Dissemination of Study Issues and Findings}

Relationship building occurred prior to the project beginning, including the foundation of mutual trust and partnering, with the sharing of power and resources in a transparent manner. A community consent for research helped to specify expectations regarding data ownership, use and analysis, right to intellectual property, and roles of parties involved, including confidentiality. I attempted to convey issues, dependent on the Carrier Sekani communities' procedures, and proceeded in a respectful, mindful, equitable manner which respected the OCAP principles of Indigenous ownership, control, access and position of data and information.

Consistent communication and consultation with the communities was necessary for a partnership to occur. Article 15 of the CIHR Guidelines for Health Research Involving Aboriginal People (2007) addresses the criteria that an Aboriginal community maintains the right to participate in the interpretation of data and conclusions, to review accuracy of the interpretation and ensure that no confidential information is included. Ownership of the data by the community attempts to prevent exploitation of traditional knowledge. 
The presentation of all findings within a cultural context, as developed by the First Nations communities is an integral part of the reporting process, with lateral communication of findings within the First Nations communities. The Carrier Sekani community decided how issues were to be presented. Recent British Columbia First Nations research by Rod McCormick (2009) and Chandler and Lalonde (2004) have demonstrated that strength-based resource identification is associated with improved health outcomes. Placing emphasis on the strengths and wisdom of community, and the Traditional ways of the Elders acted to limit the negative and strengthen the positive research findings.

Regional and provincial dissemination beyond local First Nations communities will occur only with Carrier Sekani community approval, through various organizations chosen by the Carrier Sekani, including the Northern Health Authority. The Northern Health Authority actively disseminates research findings throughout Northern British Columbia with the use of internet, publications, and media; including radio, television, and newspapers. Regional health assemblies allow for socio-political discussions regarding issues which are First Nations-community focused. The BC Assembly of First Nations represents all 203 First Nations communities in British Columbia on a national level. The BC Assembly of First Nations will be contacted to ensure that the community's research issues are shared laterally with communities and issues are brought forward nationally from the First Nations' perspective. The Assembly of First Nations (AFN) is the national organization representing First Nations of Canada, and issues affecting First Nations communities. The National Aboriginal Health Organization (NAHO) is an Aboriginal Organization that works toward improved health of Aboriginal Peoples. The research findings will be jointly submitted to the NAHO who publishes The Journal of Aboriginal Health, as this is an excellent resource for dissemination of identified health care issues.

\section{Protection of Human Subjects}

This study followed the Canadian Institute for Health Research (CIHR) Guidelines for Health Research Involving Aboriginal People (2007) in order to maximize benefits and minimize risks of harm to First Nations participants. The study conformed to the requirements of Carrier Sekani Family Services Research Review Board regarding projects involving First Nations communities within the Carrier Sekani consortium, as well as the University of Tennessee Health Science Center IRB. The study also obtained approval and followed the research guidelines from the Research and Ethics Board of the University of Northern British Columbia.

This research study required access to sensitive information regarding Traditional knowledge and information regarding views on Elder abuse. One of the guiding principles of Aboriginal research (Canadian Institutes of Health Research, 2007) that was integrated into this research project is the accountability of the researcher to understand and respect First Nation worldviews, and enter into this relationship in a reflective, respectful manner. 
Carrier Sekani community leaders, including Band council members were consulted to obtain consent prior to any individual contact of community Elders. Separate community consent was obtained from the Ts'il Kaz Koh community and they agreed to the option of a participatory research approach with collaboration, partnership, and shared power and decision-making. Carrier Sekani Family Services was initially consulted and approval was received from the Research Director, Health Director, and the Research Committee. This initial phase of research was undertaken well ahead of the planned beginning of field research activities as the process of obtaining informed consent required multiple trips to various First Nations communities. The process of consent remained inclusive of the community's decision-making processes, as well as the CSFS and Ts'il Kaz Koh processes. Potential benefits to the participants and the community were identified from the community's perspective

Concerns of anonymity, privacy, and confidentiality of informants remained paramount to the research process. Expectations were clarified and the extent of confidentiality including limitations, were clearly communicated both orally and in writing during the planning phase. Expectations of privacy and confidentiality were reviewed through individual and community informed consents, during the interview process, and throughout the research process. A community member always introduced me and my research project to the Elders, following cultural protocol.

Researchers in the past have exposed sacred and cultural knowledge, practices, and traditions without the consent of Aboriginal communities (Castellano, 2004; Holkup, et al., 2004; Salois, et al., 2006; L. Smith, 2007). The Ts'il Kaz Koh community and individual participants retain the rights to any cultural knowledge that was shared during this research. It was imperative to the research process that I addressed with the guidance of the community leaders, Elders, and other knowledge holders, an agreement regarding the use and protection of this knowledge. All uses of this information were explicitly stated within the research agreement. All reports and other documents resulting from this project will be translated where appropriate, for the community's knowledge and benefit.

Potential ethical issues included the assurance of beneficence and avoidance of exploitations of older adult participants. Safeguards included the use of informed consent with oral explanations in English with reciprocity in dialogue with Elders, Band Council and community members to minimize the risk of participation. Confidentiality of information shared during the research was described within the process of informed consent and included those instances of disclosed information which provincial law required the researchers to report to legal authorities. The criteria regarding required reporting of elder abuse and neglect to authorities was summarized in the consent to participate form.

\section{Analysis}

The data analysis was designed for collaborative participation with the related Carrier Sekani community in the interpretation of the data. Initial data analysis began with an oral review of my transcriptions with each of the Elders interviewed and changes 
were made per Elders' comments. I was unable to review interview transcription with three Elders in-person, which necessitated sending the transcribed interviews to those three Elders' homes with self-addressed, stamped envelopes. Two of these interviews were returned and changes were made to the transcribed interviews per Elders' edits. The third Elder was out of the region, and the review of this interview transcription occurred by telephone. Data was then analyzed through coding and retrieving by me and two members of my committee. Carrier Sekani Family Services Research Committee had requested that the coding of the interviews not be shared with a community member for inter-rater reliability, as previously planned, to maintain confidentiality of the Elders' interviews.

I first read the interviews multiple times and coded them independently with the data, then submitted the codes to the two committee members for review and consensus regarding the categories of each code for reliability. Codes were assigned to text from interviews according to identified concepts, which allowed retrieval of themes. Both a domain analysis and a taxonomic analysis were performed on the data. The summary of codes was then presented to the CSFS Research Committee and to the participating Elders as well as the Burns Lake Chief for convergent analysis of themes to assure internal and external validity. The CSFS community and the Ts'il Kaz Koh community were also provided an ongoing opportunity to review the entire research before the dissertation was accepted to ensure that all information was accurate and acceptable to the community and a plan to disseminate the findings was agreed and determined by consensus (Canadian Institutes of Health Research, 2007).

There were challenges with the research process. Delays were encountered in the research approval process due to the difficulty of obtaining research approval from two separate countries, as well as multiple organizations and various First Nations communities. Cultural protocol when working with First Nations communities and with Elders also required in-person communication. Difficulty in obtaining approval was compounded by my vast geographical distance from Prince George, which made preliminary introductory work difficult in a respectful in-person manner. Electronic communication was not readily accessible or utilized by many community leaders, causing delays in the research approval process and necessitating multiple trips to Northern British Columbia to meet and obtain permission for the research. Culturally appropriate communication is not electronic in the Carrier community but is traditionally oral in nature.

Another major challenge encountered was my non-Indigenous, non-Canadian resident status related to communication with the communities and obtaining approval for my research. Two of the three First Nations communities which gave initial approval for the research study decided not to participate in the research, one because the research was of sensitive nature to Elders, and the second did not respond to any of my communication attempts, both distance and in-person. Another Carrier Sekani Family Services member community provided initial approval, but withdrew the approval due to a change in administrative governance. 
Winter weather which limited safe travel into and out of communities was another challenge to the research process, necessitating rescheduling of trips when safe to travel on the roads, and when highways were open due to avalanches in the canyons. Another barrier to the research process included my mother's health, as she experienced major health issues (stroke and broken hip and numerous falls) which delayed two of the planned research trips due to the need to care for her until she became stable.

Finances have remained an ongoing challenge for the research process due to lack of research funding and the costs associated with travel and lodging and the cultural protocol of reimbursing Elders and individuals to accompany me into communities. During the research, I was able to receive $\$ 700.00$ in travel money from the Pacific Northwest Canadian Studies Consortium which partially funded my last trip to interview Elders. Carrier Sekani Family Services also provided lodging and gasoline for my initial trip to the Burns Lake area, as well as an introduction to local First Nations communities. I remain thankful for this support. 


\section{CHAPTER 4. INTERVIEW FINDINGS}

\section{Interviews with Burns Lake Elders}

Interviews occurred with six Burns Lake Elders, including two junior Elders and one Elder who resides off-reserve in Williams Lake, BC. Two of the six interviews were recorded with the Elders' permission and field notes were taken with the other four interviews. The term Junior Elders was described as including those Band members who are reaching 60years of age and are stepping up to the role of Elders within the community. Interviews occurred in Elders' homes except for one interview in the Carrier Sekani Family Services office and one interview at a restaurant, both at the request of those Elders. Three of the six Elders who participated had attended residential school at LeJac Residential School in Fraser Lake, B.C. I am appreciative of the trust of the Elders who participated in this study and for their willingness to devote time and effort into the discussions surrounding Elder health, safety, and community health. Our hope is that the collective wisdom of these Elders will help to define and prevent Elder abuse within First Nations communities.

\section{Themes Emerging from Interviews}

This chapter presents the themes that emerged from the interviews with the Elders who participated in this study. Some of the Elders wanted the interview guide while others preferred a free-form interview structure. The following questions were used as a guideline in the interviews of the Ts'il Kaz Koh Elders:

1. I would like you to think about being an Elder in your community and help me understand what that means to you.

2. Could you describe for me, what family and community relationships were like prior to Contact?

3. Can you please describe how families cared for Elders in the past?

4. For some people, the relationships that they have with family, friends, and others can be very important to them and their health. Please help me to understand how best to work with families in which Elders are experiencing violence or neglect.

5. Help me to understand how you think violence affects Elders in your community.

6. What Elders' strengths can be brought into the healing of violence in your community?

7. How can we help Elders stay in their communities and remain safe and protected? 
The interviews with the Elders were transcribed from the tape recording or from my notes, read, re-read, and from this emerged these themes. The themes were then presented back to the Elders for their approval and agreement which they gave. This work represents the Elders' stories. The Elders asked to be anonymous, but I have placed a number after the quotation or summary of what was said so you will know when one voice ends and another one begins. The quotes or summaries are indented.

The following themes identified from analyzing these six interviews are: Traditional way of life; current way of life; what it means to be an Elder; and how violence is now affecting Elders and community.

\section{Traditional Ways of Life}

\section{Communal lifestyle}

All of the Elders interviewed, described the communal nature of the First Nations communities when they were young. Interconnectedness, kinship, sharing and caring were terms which the Elders used to describe the Traditional way of life in the past. One Elder described that in the Carrier language growing up, there was no anger, no swearing. Everyone worked hard for the good of the community, sharing food and household items. Individuals identified with their clan and community. There were often gatherings, including Potlatches and dances which reinforced the communal life.

Prior to contact, the relationship was a communal relationship, it was not nuclear, and it did not have the nuclear approach that it has today. Collectively we were interdependent on one another for a variety of things. In our society when you think about prior to contact how did we sustain ourselves how did we exist to this point without all the indemnities like doctors, like all these great things we have today. We had all those things in place: We had our medicine people, we had our visionaries, and we had a system. Back then we had a hierarchy in the feast house, but at the same time within the community we also had a variety of different people doing different things within the family. And each family had these people, and some of them would interchange or exchange and some were able to go to their families or some did the whole community; dependent on the knowledge of that or the knowledge of the community or a different community: A lot of it was done collectively, not like today [respondent 5].

\section{Elders' roles}

In the past Elders were a part of the communal structure, acting as story-tellers, and keepers of Traditional knowledge. Elders raised the children and disciplined them, while teaching the Old Ways through mentoring and role modeling. Children grew up working hard as part of life. The children helped the Elders take care of the homes and 
helped with the chores of hauling wood, and carrying water. Elders relayed how they grew up with parents, grandparents and great grandparents who were involved in the Potlatch system. "My great grandparents and grandparents communicated by example, how they were practicing culture and how they framed society and culture in their own parents' ways" [respondent 3]; "The Elders were very close, they would worship, and they would sing, they would drum, they would dance, more of the cultural stuff' [respondent 5].

Women's roles in the past were described as very powerful in the Potlatch system. Women worked hard gardening, gathering and drying foods, fishing, cleaning and drying fish, sewing, cooking and cleaning. Women crocheted, mended fishing nets and also made clothes for the families. One Elder described her family life as a child: "Everyone would work. Mom crocheted, mended the fish net, and made moccasins and clothes. My mom made moccasins for the family. One pair had weasel fur around the cuff and beading on the toe. We made floats for the nets. Mom would go berry picking and dry the berries- blue berries and soap berries" [respondent 1]; "The women were the very powerful ones in the Potlatch system, they were very quiet, very efficient, and just got a lot of things done in a very short amount of time. The Potlatches would come as a surprise to us and we would have to have a Potlatch and I was just amazed at how effective they were in getting business done" [respondent 3].

Marriage usually occurred within the First Nations community. One Elder described how his mother married outside of the First Nations community, causing her to lose her First Nations status, and was then forced to live a very hard existence outside of the community. "It was hard back then for women who married outside of First Nations" [respondent 6].

Women taught the children to understand others and taught the children to love themselves and others. Mothers and aunts were active with Elders regarding the Elders' care and welfare within the communities, as described by the following: "In the past, Mom and Auntie would take turns caring for the Elders" [respondent 3].

The Elders weren't taken care of in the past; they were part of the process. They were totally part of the process you know. The Elders were there, they were there for their background knowledge, you know. There was no hierarchy within the family, it was all based on respect and a lot of etiquette aimed at these Elders. This has changed and in the past when an Elder knew it was their time knew their contribution wasn't going to meet the day's needs, and if they were going to be a burden, they would simply up and go out beside a tree and wait until time ended for them, that is how they dealt with it. No one made a decision to euthanize them or anything it was up to them to make that choice. If they aged or became feeble the extended family looked after them until it was over, people would try to extend their life for as long as they could. There were two incidents within the last 10 years when Elders from another village have done that, a couple of years apart, they would sit there would wait until it was finished. That is what went on in the past. There would be a lot of interaction until 
the possibility wasn't there anymore and then it's just a decision on the Elder's part to do what they had to do. The Elder would die from natural consequences, mostly, I don't look at that as the Elders weren't looked after, they were the lookers after, and they were part of the process always [respondent 5].

Men fished, worked trap lines, and hunted for food, going in groups or pairs, and distributing the meat to the entire community. There was respect for the earth and for the animals. Everybody had a role in hunting and fishing, and the whole community, including the young children, would help pack the meat back to the homes. One woman recalled as a young girl being given a section of a moose which was just killed, to carry back to the community. Working together and providing for the entire community were part of the Traditional ways. as described by the following stories: "Being an Elder means respect by Elders and the community. Growing up with my grandparents there were quite a few Elders. My grandfather taught me about the trap line and showed me how to set traps. He told me never to make fun of an animal. We would catch foxes and beaver" [respondent 2]; "They would work together. When they went hunting, they would go in groups or they would go in pairs, and they would distribute meat, where today, people go hunting here, and they don't share even a scrap of meat. Some of them will get two moose and they don't share it. Families are really quite isolated and stick to themselves, kind of a lack of community within the old ways" [respondent 3]; "I remember my great grandpa shot a moose and he came back and got every other available hand and I was a little girl and I even got a piece of meat to pack and that was heavy. Everybody worked together" [respondent 3]; "I was carrying firewood at age 5 to help" [respondent 6]; "I think back on Elder ways, and where other people needed help. It is not an enabling kind of help, but just a caring kind of help" [respondent 3].

\section{Family structure}

Everyone operated from within his/her family setting with defined roles. Grandparents took over the role of raising the children with the parents and acted as protectors and mediators. The grandparents would raise the children and discipline them, to allow the bond between children and their parents to stay intact, while creating strong intergenerational relationships. Aunts and uncles also had a role in raising children and disciplining. The interconnection within the generations and between communities allowed everyone to have a role in the children's lives. "When I was 11, my Grandmother was 96. We would help our mom and auntie. We would sew with the hand sewing machine. The boys would cut wood. We would take turns working. Not now, we turned white!" [respondent 1]. Another Elder described family structure:

If you look at our communal living it was a lot of circle stuff a lot of sacred circle stuff, you know. Everybody was able to operate within their family setting, you know. In your family setting you had your grandparents. Grandparents took over the role of the parents. The parents basically produced children and the grandparents raised the children, and 
that's how the cycle went. Then when children got old enough they would become the grandparents and would raise their grandchildren. There was a lot of interdependence on the Elders and the young and that is how knowledge was passed down; Grandparents directly interacting with the grandchildren. Your discipline wasn't done by the parents because, when you discipline a child, it creates distance regardless of the type of discipline, and parents did not want to create that distance. I don't know where that old model came up, but it evolved over time and parents did not want to be the ones who created distance with their children, so the aunts and uncles would be the ones who would look after the discipline of the children, and the loving bond between the child and their parents would stay together [respondent 5].

The families in which the children were raised were large due to the extended family structure with aunts, uncles, grandparents and cousins. The Elders all described a strong bond within families and throughout communities with both an inherent interdependence and interconnectedness. One Elder referred to his family's strength which bound them together, and how children shared what they had between them. Children's toys, books, bikes were freely shared between the children, and if a child was not riding a bike, another would be using the bike. "My parents worked hard. My father would go out trapping and we would help mom. We did not have electricity. We would clean, sweep, do the dishes. We washed clothes on a washboard. Family life was good. In the evening, my father would help us say our $A B C$ 's; he was very patient" [respondent 1]; "There was one radio for the whole family. There was no such thing as oil stoves, just wood heaters. We would carry water up and down the hill; it was everybody's job" [respondent 6]; "We were not jealous of one another, we were tight knit families. We would go swimming at Stuart Lake. I took it for granted how well we got along" [respondent 1]

\section{Hard work as a form of caring}

Hard work was inherent to the Traditional lifestyle. The children grew up working hard to survive, cutting wood by hand, carrying, splitting, and stacking firewood for heat and cooking. It was not until 1949 that the community had electricity. Hard work was described as a form of caring and connection to others in which the children learned values. "Mom was 84 when she died, but she looked 65. She taught us to understand people and to love our self and others. She would teach us to be ladies- this was hard though-we were climbing trees and fences" [respondent 1]; "We had chores to do. Chores taught cleanliness" [respondent 1]; "Growing up, there was farming. Our family's strength bound us together. My Aunt helped, there were cousins and always lots of work to do. We had big gardens to tend to. In the winter, we would punch holes in the ice and catch white fish. We worked hard as kids to survive. We cut wood by hand with hand saws, no chain saws. It wasn't until 1949 that we got electricity" [respondent 6]. " 
I think back on Elder ways, and where other people needed help. It is not an enabling kind of help, but just a caring kind of help. We have the best of both worlds, we have research. My brother has got a lot of good information from mentors on the prairie and got his knowledge from that area. We do have Elders brainwashed from the Residential schools. But if you think of our childhood, there is enough from a lot of different sources, as you get older you realize how important things are, you realize that you got a lot of information. I was talking with my older sister and we said it is amazing how much we really remember and got and we didn't even know we were learning it [respondent 3].

One Elder described how she gained her love of learning from her Grandfather, as learning was a natural part of life in their home, with her grandfather learning French from his record player:

I get from my Grandpa another thing that I valued from him is his love of learning and I found that to be very interesting as he spent all this time in the Residential Schools, but that man would be in his bedroom with his record player, learning how to speak French with it. I find that interesting, versus some of the Elders now, more "What can I get for being old?" versus the Elders I remember who were very hard workers, traditional, trapping, fishing; didn't have a lot given to them. And the kinship was so tight with the Elders that I know. The women had an amazing network with other women from Reserves far and wide, and when one was in trouble, they'd all come [respondent 3].

\section{Changes from the Traditional Way of Life}

The next theme that emerged was that of the changes that have taken place from the Traditional way of life. The Elders all reported that there have been substantial changes and that many of these changes are not for the good of the community.

\section{Forced relocation}

The Elders described how the Canadian government forced families to move from their Traditional Lands to reservations. The extended families were reduced in number of members, and small family units were required to move into small houses on reservations (Figure 4-1). Many extended families were placed on separate reservations. One Elder remembers growing up in a family of 12 until the government moved them into town, and forced them to relocate and reduce the number of family members to four: "We had extended stays. When I was 2 years old, I lived in a family of 12 and when the government moved us into town, my family was brought down to a family of 4 of us. All of my extended family was taken away from me and we were stuck in these little shacks on the reserve and life changed for us. So there was a lot of interconnection, interdependence, everybody had a role in their life you know, the parents did what they had to do, the grandparents, the aunts and uncles" [respondent 5]." 


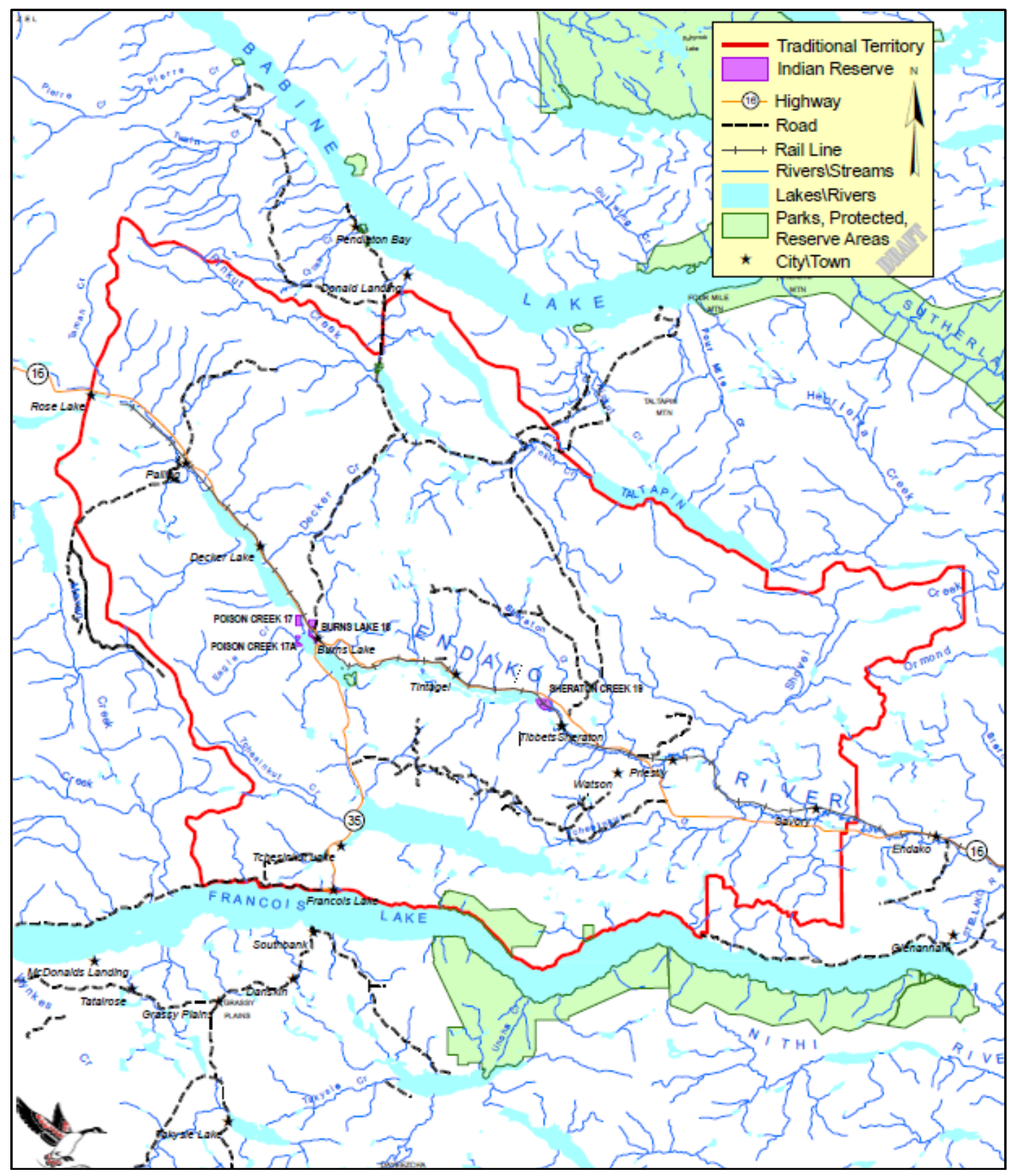

Figure 4-1. Carrier Sekani traditional territory and Indian reserves.

Source: Adapted from Carrier Sekani Tribal Council (2012). Ts 'il Kaz Koh First Nation tradional territory. Retrieved March 6, 2012. Retrieved from http://www.carriersekani.ca/images/docs/burnslake/Tsil_Kaz_Koh.pdf 


\section{Residential schools}

Children were removed from the families by the Canadian government and sent to Lejac Residential School in Fraser Lake. Elders described long-term abuse at Lejac and how regimented their lives became, beginning with being awakened at 5:50 A.M., in the dark hours of the morning by a large bell. Children would then be required to get on their knees to pray to the Virgin Mary. They would then go to the bathrooms, which the children were fascinated with, as they did not have flush toilets on the reserves. There were no Traditional foods served at Lejac and breakfast always consisted of oatmeal and toast. All of the children wore uniforms. All three Elders living on-Reserve, who participated, attended Residential School at Lejac. "I spent 10 years at Lejac; I was discriminated by the school superintendent. There were 16 Residential schools in BC; all run by the Roman Catholic church. The principal was a priest. I didn't know how to speak English. I knew 2 dialects: Moricetown and Wetsuwit'en dialects" [respondent 4].

\section{Loss of language and ceremonies}

At Lejac Residential School, the children were not allowed to speak their Traditional language and were beaten until they spoke only English. Two Elders described how they were physically abused over the course of the first year at Lejac because they did not know English. The children spoke Carrier and various dialects in their family homes until they were relocated to Lejac. At Lejac, they were not allowed to speak their traditional language, only English, and they were beaten 'black and blue' until they learned English. This resulted in the loss of the Traditional language and dialects with these two children. "The nuns would take leather straps to our neck. My grandparents spoke to us in Carrier and when I went to residential school the teachers told me to speak English. I didn't know a word; I didn't know what English meant. They took a long leather strap and beat me until I would speak English. I got beat up a lot, because it took me a year to speak English. My neck and back and my arms and hands would be black and blue. I was abused by one of the teachers, a nun in grade 8" [respondent 2]; "In the past, I was sent to Catholic school, with Father McCanahan. We wore uniforms, blue shirts, corduroy pants. He would tell me "You can't come in unless you speak English". There was a big thick ruler that they would hit me with. I had black and blue arms. My dad was in World War II and he saw a lot of bad things, when he saw my arms he wanted to go beat them up. I learned to forgive, but I never put my kids in there" [respondent 2]; "The Elders would talk to us in Carrier, but they never expected us to answer them in Carrier. We always answered in English though they spoke to us in their language. I think that this harps back to their schools where they were punished for non- English speaking. It is one thing I regret. I can say all the words and understand the words when I hear them, but I can't speak fluently. And that is another thing we lost. The Elders, when I was growing up, could all speak Dakelh" [respondent 3].

Brothers and sisters were separated, as boys and girls were not allowed to be close to each other, and had to sit on separate sides of the room. They were not allowed to play together, due to the nuns and priests fear of sexual activity. The Elders, some in tears, 
described the ongoing physical and sexual abuse by both nuns and priests at Lejac. "We read the 10 Commandments each night. No priests or sisters can sexually abuse children with the 10 commandments" [respondent 4].

\section{Loss of roles}

Traditional roles were lost when the family and community structure changed from a communal form with extended families to that of small nuclear families on separate reservations. The roles of grandparents, uncles, aunts and parents were taken away from the community without children in the communities. Parenting skills were lost, and the caring, communal structure of the culture was obliterated due to forced relocation, separation of families, and removal of the children. Elders described how families became isolated with a shift from a sense of community to watching out for one's own needs to survive.

Another change from Traditional ways was the loss of the Elders' role of storytellers. First Nations' ceremonies became outlawed by the Canadian government, and with the absence of children in the culture, intergenerational relationships were not formed with the role of the Elder as teacher, storyteller. Along with the loss of storyteller role was the loss of the stories which is an oral form of First Nations history. "With my mum, in the oral Tradition everything was in her head" [respondent 3].

\section{Loss of communal structure and values}

Hard work within a communal community structure, and traditional family roles were not valued in contemporary society. All of the Elders remarked in their stories that everyone worked hard in the communities when they were young, and that work was a form of caring which connected the members and taught the children the value of working together, bonding the generations and communities. The loss of the value of hard work for the good of the community also meant losing the Traditions associated with that work. Fishing, hunting, farming, gathering and food preparation changed from a communal form of caring to individuals providing exclusively for their own nuclear families. Purchasing outside foods, instead of group preparation of foods, became a part of the culture and was described by one Elder as becoming 'White.' Others commented: "Mother was strong, she would go out fishing, and then gut the fish, and dry it and freeze it. She knew how much we needed for our family. Me, I buy salmon" [respondent 1].

I started very young, looking out for my Grandma. I would work like crazy. I would do all the wood, I would do water, you know, packing water, packing wood, cleaning the house. The women worked very hard for their grandparents, not because they asked. I don't remember them ever asking, just because you could see what needed to be done and you 
would do it. Today nobody has got to do anything unless you pay them, so that is a huge difference. I don't know....there was just more caring and more connection with the Elders, more respect.... Kids just pitched in; there was a lot to do and there was no money. Today, people have wood burning stoves and they expect the Band to bring them wood and chop it and pile it; back then, we had to find it, carry it back to our place, and chop it and pile it ourselves. We were very hard workers [respondent 3].

When I was young, youths would pack water. Auntie and Uncle would work; we would carry water and wood, because we did not have electricity or water. Now my nephew has no education and not working. I was working at his age in construction. In underground maintenance, I hated that job. I was there 3 years, and I got sick and tired of that job. You could hear the ground shift when you were underground. Kids now a day don't help. When I was a child, I helped by splitting wood and with chores. Elders tend to help themselves now [respondent 2].

\section{What It Means to Be an Elder}

During the interviews, Elders described what it means to be an Elder now. Being an Elder includes giving advice and being respected. The importance of returning to Traditional ways after Residential School, including the Traditional role of storytellers, was discussed. Elders' words, wisdom, actions and knowledge create a connectedness and kinship with others. Being an Elder is about providing advice to others regarding their behavior, including advice about anger and alcohol, while remaining nonjudgmental. "Being an Elder is about leadership..... Giving advice about how a person behaves- like anger and what causes anger. What alcohol does for them-I tell them: Do you want alcohol to control you or do you want to control alcohol? [respondent 1]; "Being an Elder: something I would call ultimate respect for me" [respondent 4].

That status of Eldership, you know, if the Elder is a well-balanced human being, just about anything that comes out of that Elder's mouth is useful, you know. Regardless if it is how to cook a roast or skin a moose or whatever, if it is to deal with an angry sibling, upset in-law or something, they have all gone through a certain amount of experiences in life and we can benefit from what they know. Elders can talk about certain situations and how they handled it and teach us a lesson you know, our lessons were all told in stories at one time. One of the things our society is losing is our story tellers, you know you see the impact on that in the actions of the young ones, they all belong to gangs. I may be paint brushing them, but a lot of our young people end up in gangs, and it is just silly, because it is the loss of that identity, you know, and I think that is what the Elders bring to the community, who we are, the roots of warrior trees standing" [respondent 5]. 


\section{Balancing Traditional and Christian beliefs}

Being an Elder includes balancing Traditional and Christian beliefs while bringing Traditional knowledge into everyday living. The loss of the Traditional way of life and the resulting legacy of the Residential Schools was described by two Elders as a major issue. "I think that our people need to come to grips with some of the old ways; we can't rely on the churches for some of the stuff that we practice. Some of the rituals should be brought back because it strengthens that identity of the younger generation right now. There are medicine people all over in Indian country but they are not really given the accolades except within the Indian community, they are, but mainstream is slowly catching on, it is taking a few years" [respondent 5].

And what I see in that group (current Elders) is caring. Caring about people, caring about the little guy, caring about the ones who fall through the cracks, caring about the ones stranded, are they all right? Everybody counts when they are old. We have some Elders from long ago who have that. Some of the Elders who don't. We have our own mind. We have choice, choice of religion, choice of activities, choice of partners, and have a lot more choices than our Elders who were incarcerated and brainwashed. What I see with the Elders today that they are brainwashed and they are still stuck in the Residential School politics. I can't accept it, I don't buy it. I think that is a big thing with the freedom that my generation has. We grew up poor and we grew up with the extension of Residential School but there was enough with the Elders to latch onto what they had. A lot of stuff was lost, but there was enough there for this generation. I think the other thing in what an Elder is to me is that some of them are going back to the Traditional part and they integrate both Christianity and the Old Ways as well" [respondent 3].

\section{Leadership and caring}

An Elder acts as a resource for useful Traditional knowledge with his/her years of experience. Leadership, caring, respect, connectedness, and translation of Traditional knowledge were also described as components of being an Elder. One of the Elders used a metaphor to describe the responsibility of safe-keeping and integrating Traditional knowledge as: 'Elders are the roots of warrior trees standing.' "Those are mentors and role models, and I don't see that today. I think that even from my Grandma's generation to my mom's generation and that is the generation of the Elders we have now, the parenting was not what it should have been and you've got the younger generation who is quite messed up, struggling, lack of relationships or abusive relationships" [respondent 3].

Being an Elder in the community for me is that you are there to provide some type of cornerstone leadership and that's to do with the etiquette of 
your community as it operates daily within the larger community of Ts'il

Kaz Koh. So for me being an Elder is basically that you are

nonjudgmental and to be, if ever needed for advice or assistance and to be

able to give that, you know. An Elder accumulates years of different types

of life experiences that preclude some of our other people, and they know

shortcuts that would benefit them because there are pitfalls in those

shortcuts. Elders have experienced life and death stuff and incorporate

that into their role as Elders; shaping those types of things that were

taken over by the churches you know at one time; People were led to

believe that you are either right or wrong, but life is a little more broader

than that I think [respondent 5].

\section{Keepers of Traditional knowledge}

Elders' knowledge was described as being useful to many regarding survival and knowing shortcuts which connect Traditional ways to current life. Elders were described as having deep-rooted experience and knowledge of Traditional ways which include survival skills in the bush and tracking and hunting knowledge. The role of an Elder was also differentiated from those who want to be rewarded for sharing knowledge.

It is like that with a lot of Elders I see walking around town. Someone can be walking around town and people will say "Oh that guy is just a drunk". No that guy is not just a drunk, he knows how to read moose trails, he knows where to go, where the back trail is going to come out. He knows what time of year to hunt, he knows how to live in the bush with no blankets and utensils, he doesn't need a camper, and he can go live in it. Not only that, in order for that person to survive, he had to have skills to make it to today. Surviving on those skills; that is what the Elders have [respondent 5].

\section{Current Family Characteristics}

Current family structure consists of nuclear families living on the Reserve or offReserve. Individuals identify with their individual family names, as compared to clans. The Elders remarked on the competitive nature of present-day families and how isolated and fragmented they have become from each other; driven by buying things for their individual families. "Family is a different environment now; everyone is outdoing one another. They don't pay attention to the kids. We shared what we had. Everyone shared, but kids now don't know how, they want their own" [respondent 1].; "You know, we live in box homes, and we identify each other by family names and not clans, so things have changed a lot" [respondent 5]."

Raising children has changed without the extended structure of the families and inherent loss of intergenerational relationships with the Traditional family and community structure. Parents are now the primary care givers, providing the discipline 
and raising the children. In current society, Elders have lost their Traditional roles of childrearing as grandparents, aunts and uncles. There has been an associated loss of Elders' productivity within the community and resulting isolation of Elders.

I don't see that much today, and the different generations were very integrated, but today, I see cousins and even nephews and nieces are more the white man style where the family is this family and that family versus a big communal family. Because of the nuclear setting, you have mother and father raising the child and doing all the discipline and the rearing of the child and like you said, your daughter will come and visit and say

"Would you look after this child for a certain amount of time?" but it is not extended [respondent 5].

\section{Current Community Structure}

There remains an absence for Elders' roles of /storytellers, providers of advice, and keepers and translators of Traditional knowledge within the community. The Elders interviewed voiced a desire for input into community to share their knowledge. "There used to be community involvement, communities would help another community. Years ago there were doors kicked in and the Tribal Council stepped in and stopped it" [respondent 2].

As Elders, as I think about myself, where is the venue for Elders in this community? There really isn't, so I think there needs to be more outlets, more possibilities for Elder gatherings, there is a finite number of Elders in our communities. There is not 10 million people you need to look up, there is just so many. There should be a list of every Elder in the region, you know. Somehow to tap into this brain system that we collectively own and pull out the stuff that we need to know from them. Right now I see the Elders are stuck in the back of the room completely ignored, you know, and pompously brought out for TV's and photo ops etc. They are not given that validity enough [respondent 5].

\section{Violence Affecting Elders}

Residential School violence was described by the Elders in a historical context as children at Lejac Residential School, and as adults, in the form of residual trauma. Elders described abuse of Elders that occurs by younger members of their families and community as well as financial exploitation related to Elders' Residential School settlement monies. 


\section{Drugs and alcohol and financial exploitation}

Though leadership and respect are both identified as inherent to being an Elder, Elders do not currently have a role in which they are able to influence violence or drug and alcohol abuse in families or communities. Young people were described as exploiting the Elders by taking their money to buy drugs, using the Elders' phones and charging long-distance calls, as well as taking the Elders' cigarettes. Elders have to pay the young people to obtain help in their homes, and for the young people to show affection. The current abuse was described as occurring to the Elders in their homes. "There is verbal abuse, lack of respect, kids want to bum some smokes, want to use Elders for their money. Sometimes people want a ride home, want money, want a smoke, or to use your phone. I had a \$200 phone bill one time from them using my phone [respondent 1]; "I never got violated in any manner. Someone come to my door and punch me; nothing like that" [respondent 4]; "In the past this (Elder abuse) would not be tolerated. There were close interactions, it was communal. Elders were respected and people would step up" [respondent 5].

First and foremost it is almost like being incarcerated in your own home, when you are hiding in your own room, it's like a social jail system because there is someone in your family or your neighborhood that's terrorizing you. It shortens their life span, that stress and that kind of living. Elders in the past didn't have the language skills to convey the types of ordeals they were individually going through. I think that it cost lives. And today, I think because of the nuclear living, some of the Elder abuse brought on by the addiction to drugs is not being brought out in public and it is a slow death for those Elders by being brow beaten to your death by your sons and daughters. I've seen the strain on Elders where they try to come up with money for their child to support their habits- with the Elder not really knowing why the person really needs the money it is an unnecessary strain. I think it shortens their lifespan you know and the quality of life. The quality of life suffers and when you're being terrorized; your eating habits, your sleeping habits, your health, everything you carry, it impacts you all around and the collective community, if it is strenuous enough, we lose an Elder. We lose collectively [respondent 5].

There is no funding for care of Elders in homes or for care of children who have alcohol and drug problems. We need more money for homes for Elders to keep them safe, and programs for alcohol and drugs to keep the kids drug free. There is no help for them or for their families to get help for them. There are not many homes to care for Elders in this community. Elders are not safe sometimes in their own homes. There are drugs and alcohol all over the province- too much TV, computers, cell phones. I don't care where you go [respondent 6].

I think that it all comes down to money. What I see is with the neglect of Elders it is when they have money. I don't know why that is, as I could 
never imagine doing that to my grandmother. As a matter of fact, she would give me her money to safe keep it for her. If you did that today they would spend it. I think that maybe it is lack of respect, I don't know, it is confusing to me. To use Elders for money, to be verbally abusive to them if they don't get what they want. I've seen that, and I would never have seen that in the past growing up in the past because it would never be tolerated. No one would get away with that, so there has been a huge breakdown somewhere. I think one thing that comes to my mind now about Elders' roles is that there is a lot of violence in families and the Elder has no say; they can't do anything about it. I think that elders enable the violence from different members of the family. Actually I've seen Elders do a lot of enabling, that have sons who are into drugs or are alcoholic and they are enabled, and they probably could stop a lot of the destructive behaviors of the kids and the grandkids but they don't I can't imagine, as I never went to Residential School, so I'd be different. I don't know what it takes, that little something else that keeps you on the straight and narrow to avoid self-destruction [respondent 3].

I started young working, carrying sacks of wood. Women worked hard cleaning, cooking. There was caring and connection. There was no money, kids pitched in. Now the band is expected to produce. Now when Elders have money, it is spent. In regard to quiet rules: There is not so much now, I think that's missing. I think the roles aren't respected. With Elders, it is what they can get out of them, financially wise now instead of wisdom/ in the past it was more culture and wisdom related. Now how much are you going to give me for showing you love? That is with the Elders who have money from Residential school. That is a sad picture. I see people getting it and nothing changes, and it is gone just as quick as they get it [respondent 3].

\section{Ensuring Elder health and safety}

Elders commented on the responsibility of the Tribal Council along with the collective community to ensure the health and safety of Elders. The importance of keeping abreast of Elders' living situations and their needs was stressed, including the creation of a venue for Elders' input regarding the health and welfare of Elders within the community.

The community was cited as needing to have local activities to avoid isolation of Elders and improve communication between generations and the sharing of the Elders' knowledge. The importance of interconnectedness within the community was stressed, and a committee for Elder health was suggested as well as community- based alcohol and drug abuse programs for families. Sports and Traditional activities such as fishing and hunting with the young people allow the Elders to connect with different generations and share their knowledge. 
Community can have activities for families: Games in the evenings, baseball team, skiing, skating. Keep their mind from alcohol and drugs or whatever they are using. Bring them to treatment, have Alanon meetings. "On the weekends, the Band office can have dancing and entertainment" [respondent 1]; "Community is involved with Elders, separate from the Tribal Council. I think a Community Safety Committee for Elders is a good idea" [respondent 2]; "Kids need sports. My grandkids are fishing; we get up and take them fishing from 7-5 so we can pass this knowledge on. We had a big garden and there was plenty of meat (growing up). Everybody had a hand in hunting and fishing. It just happens when you grow up with it. Now I am teaching my grandchildren to hunt and fish so they grow up with it" [respondent 6].

Be vigilant to them, always be vigilant of your Elders and have an awareness of their total living condition, their type of residence and how we can make their life better. As a Chief and Council that was one of our main goals in life to eliminate some of the physical hardships of the Elders and provide the amenities that are out there that they should have access to and can have access to. It is being considerate and thoughtful of the Elders. I think that if the Elders suffer in violence that the violence is going to be taken to understanding from the social makeup of first the individual families and the social make-up of the collective community. We have to as communities not relay on the agencies to solve our problems, we have to, in the communities, know who in the community we can rely on to help us work through these times [respondent 5].

There is a need identified regarding the creation of roles for Elders within the community in which their productivity would be promoted and their knowledge shared. It was suggested that through the utilization of technology, a new form of interconnectedness could occur.

Today technology is a useful tool, and if you can amalgamate the tools you have in the technological world with some of our Elders' brains, can you imagine the product you could pull out of it? We've got to find a way to bring the Elders to the technological stage because you can't just retire them to a home. Once they've finished their process of making a living, they are still living, so you need to find a way to tap into their brains. Take what they have. What good is knowledge if you don't share? If you are not given the opportunity to share, then it is a catch 22. So I think that it will happen. I see it happening more and more, that First Nations philosophy is getting out into mainstream some of the ceremonies, it is slowly evolving and we are being treated in the mainstream. That's all I can say. When I tell people that for centuries that we lived here, it must have taken some brains to manage how to manage to survive [respondent $5]$.

Evident in the interviews and analysis is the level of resiliency of these Elders to cope with the amount of devastating events they have encountered. The descriptions of 
loving, caring connections in the past and the desire for a renewal of the communal nature of family and community conveyed the Traditional values of caring and desire to share and connect with the community. The Elders described ways of dealing with adversity by bringing back the Traditional values and maintaining a balance between Traditional beliefs and Christianity. When I moved back home, I relearned what my mom and dad had taught us....gentleness. Before my mom died at 84, when I said "I love you", she told me "I love you 4 million times more". I thank God for the trees, I thank God for everything. Live for this minute, life will change; you create what you are. If you live with animosity you will be a rough neck; you think and say what you are. My mom told us; "Use your mind". Too much Lejac Residential school in my mind" [respondent 1]. 


\section{CHAPTER 5. LESSONS LEARNED FROM THE ELDERS}

\section{Introduction}

In this study, I sought to respectfully understand Northern British Columbia First Nations Elders' views regarding the health of communities, intergenerational relationships, Elder roles, and violence using a community-based participatory research design. The aims of this study were met through dialogue between myself and Elders in the Carrier Sekani Family Service area who described the interface between traditional First Nations belief systems, healing methods, and the current health care systems in regard to violence. I was able to establish a research partnership with the Carrier Sekani Family Services and had the honor of working with the Elders of the Ts'il Kaz Koh First Nations (Burns Lake Band).

\section{Findings Related to the Aims of the Study}

The first aim was to explore how First Nations Elders understood violence in their communities. Themes related to the problems of violence were multiple, including changes from Traditional way of living to contemporary way of life, changes from the Residential School experience, loss of Traditional roles, and change in community from communal structure to that of nuclear family units, and the influence of alcohol and drugs on individuals and families. Sub-themes related to violence included the loss of intergenerational relationships, changes in Elder roles from the past, and the change in roles and behavior from the past across all ages. Also identified as sub-themes were the influences of change from that of communal caring, to individuals watching out for their own welfare, and the change from hard work being valued within traditional roles to lack of value for hard work in contemporary society. Disruption of intergeneration roles within the community was also identified as a theme related to violence.

The second aim of the study was to explore Elders' views on what gives rise to violence in First Nations communities. The First Nations Elders interviewed discussed the relationship between the changes in Traditional lifestyles to the current lifestyles and the introduction of violence into the communities. The Traditional communal structure was one in which the values of interconnectedness, caring, and sharing were exemplified through hard work and providing for the welfare of the community. What was striking from the Elders' stories was the cohesive, gentle culture of the First Nations community when the Elders were growing up. Colonization and associated changes resulted in the loss of communal structure and values, loss of language and ceremonies, and loss of Traditional roles; as the First Nations Peoples were not allowed to practice their cultural beliefs under penalty of law. Many extended families were placed on separate reservations, as part of the systematic cultural deconstruction by the Canadian government. This created isolation of family members and reservation communities in which people were crowded together in small dwellings, grouped not by families and clans, but by geographical locations. 
The third aim of the study was to illuminate the factors that First Nations Elders view as affecting the safety and wellbeing of Elders living in First Nations communities. Financial exploitation and physical abuse of Elders were identified as occurring within families. Drug and alcohol use and the loss of extended families and communal relationships were brought forth as other factors affecting the wellbeing of Elders. Exploitation of Elders was described as occurring for money, food, cigarettes and the use of their house by younger members of the community and family members. Young people were described as displaying a lack of respect of Elders through the withholding of affection or help to the Elder until the Elder would give them money or desired goods. This lack of respect and creation of a power differential within contemporary intergenerational relationships reinforces a conditional nature of affection and acknowledgment, which acts to further victimize Elders.

Aim four was to explore First Nations Elders' narration of intergenerational relationships before and after contact. A major theme pertaining to intergenerational relationships was the collective nature of the culture with a communal structure, prior to contact. There existed an interconnectedness and circular nature of the extended family out of which people operated prior to contact and grandparents had a strong role as the primary caretakers of children. The Grandparents were responsible for the rearing and discipline of children which created interdependence between Elders and the children. The loss of Traditional roles and communal structure, according to the Elders, changed how children were raised. Parents are now the primary care givers in contemporary society, providing the discipline and raising the children without the extended communal structure of families and inherent intergenerational relationships which existed in the past.

In contemporary society, the Traditional roles of Elders in regard to grandparental childrearing and teaching of Traditional language have been lost. This has created distance between generations and loss of Traditional knowledge translation, as well as the traditional etiquette and respect aimed at Elders. After colonization, the attempt to balance Traditional and Christian values has been a recurrent subtheme for Elders. Post colonization, family structure changed from communal living on Traditional lands, to that of nuclear families living on or off Reserve. Identification changed from that of a clan member to that of an individual, based on his or her family name. The Elders remarked on the competitive nature of present-day families and how isolated and fragmented they have become from each other; driven by buying things for their individual families.

The final aim of the study was to clarify factors which First Nations Elders viewed as required for Elders to live safely within their respective communities. The Elders interviewed voiced a desire for input into community to share their knowledge. They also identified a need to create roles for Elders within the community in which Elder productivity is promoted and their knowledge shared. There currently is no venue for the Elders' roles of /storytellers, leaders, providers of advice, and keepers and translators of Traditional knowledge. A new form of interconnectedness could occur for the Elders through the utilization of technology. 
Evident in the interviews and analysis is the level of resiliency and humor that these Elders displayed in coping with the amount of devastating events they have encountered. The descriptions of loving, caring, connections in the past and the desire for a renewal of the communal nature of family and community conveyed the Traditional values of caring and desire to share and establish intergenerational connections within the community. The Elders described ways of dealing with violence and associated drug and alcohol use in the community by bringing back the Traditional values while maintaining a balance between Traditional beliefs and Christianity.

Elders also commented on the responsibility of the Tribal Council along with the collective community to ensure the health and safety of Elders. The importance of interconnectedness within the community was stressed, including the creation of a venue for Elders' input regarding the health and welfare of Elders within the community. The community was cited as needing to have local activities to avoid isolation of Elders and improve communication between generations and the sharing of the Elders' knowledge. A committee for Elder health was suggested as well as community based alcohol and drug abuse programs for families. Sports and Traditional activities such as fishing and hunting with the young people would allow the Elders to connect with different generations and share their knowledge and experience.

\section{Discussion}

\section{Colonization and decolonization}

What was striking upon hearing the Elders' stories is the long-term effects of colonization with the disruption of culture and resulting legacy of violence, drug and alcohol use and loss of intergenerational relationships. In Chapter 11 of Reclaiming Indigenous Voice and Vision, Laenui (2000) discusses the steps of the colonization process as observed by the late Dr. Vigillo Enriques, of the University of the Philippines. The first step of the colonization process; denial and withdrawal, occurs when the nonIndigenous colonizers deny the existence of the Indigenous people's culture, values and norms. The result of this action is a reaction of the Indigenous community to withdraw from practicing their cultural practices.

The second step of the colonization process is the systematic destruction/ eradication of physical symbols of the Indigenous culture. This destruction intensifies within the third step of denigration/belittlement/insult. Newly formed systems act to criminalize Traditional practices, condemning those who choose to maintain Traditional cultural beliefs, occurring within institutions of education, health care and judicial systems. In the case of these Elders, all cultural practices were criminalized. In the fourth stage, surface accommodation/tokenism; the Indigenous become something that the dominant culture describe as eccentric and which the colonizers have accommodated and now tolerate. The final process is that of transformation/exploitation in which the surviving Indigenous members are forced to assimilate into the dominant society. Beliefs, 
language, and symbols are transformed into mainstream culture, utilized and exploited for the benefit of the non-Indigenous culture.

Laenui proposed five steps of the cultural recovery process for Indigenous peoples to take within the process of decolonization. The first phase is termed rediscovery and recovery, in which the colonized, who have been in a state of inferiority, rediscover historical traditional practices and begin to recover the culture. The lens that some Indigenous are using to view recovery is actually from another culture due to the long-term forced separation from their Traditional belief system. The stage of rediscovery leads to the second stage of recovery, mourning the loss of Indigenous identity that has occurred with colonization. Anger regarding victimization occurs during this phase along with associated violence, anger and adversarial status. Dreaming is the next phase, in which hopes and aspirations surface, and self-determination becomes a reality. Commitment to a single goal is the next step which leads to the final step of the cultural recovery process of action in which objectives are carried out (2000).

The Ts'il Kaz Koh Elders interviewed described the colonization process and the desire to reinstitute some of the Traditional First Nations values of sharing, caring, hard work, respect, leadership, and the re-establishment of their Traditional roles as Elders within the community. The Truth and Reconciliation Commission goals are also consistent with the rediscovery and dreaming phases of the cultural recovery process by Laneui (2000).

\section{Residential school}

The forced relocation from Traditional lands to Reserves and changes from an extended family to a nuclear family structure resulted in the loss of intergenerational relationships. The profound abuse of children during their Residential School experience and the stripping away of Traditional ways during the Residential School created generations of children who were not parented due to the children being removed from their families. The loss of children from the community and their concurrent abuse within the Residential Schools disrupted the social structure and introduced violence into the childrearing process within the First Nations culture. A legacy of resulting anger and alcohol and drug use occurred within communities. This has created many people throughout generations, who experienced a lack of parenting and a lack of loving, gentle relationships which were replaced with abusive relationships (Akhtar, 2010; Battistte, 2000; Changfoot, 2009; Czyzewski, 2011; McDonald, 2007).

The trauma of residential school was woven throughout each of the interviews that took place. The number of documented cases of widespread physical, verbal, and sexual abuse of the children attending residential schools is increasing with the progression of hearings held by the Truth and Reconciliation Commission (2012). The commission hopes that the stories regarding residential schools will help to foster the global understanding of long-term social, cultural and health impacts of the residential schools. The associated historical trauma of the First Nations Peoples has affected each 
generation and these effects will need to be identified in order for health care systems to adequately support the First Nations communities in their healing process. As more stories come forth regarding Lejac Residential School, the stories will provide a framework which can be used to form direction for the funding, development, implementation, and evaluation of programs which are directed toward justice, reconciliation, and healing of communities. As McDonald (2007), expressed, a model of trauma particularly the trauma of holocaust victims provides a template for Indigenous communities to describe the intergenerational effects of violence and cultural genocide. The study of historical trauma through the recalling of stories affords the ability to focus on individuals to foster their healing as well as their families and communities, while avoiding generalizations about First Nations residential school survivors.

During the writing of this dissertation the Truth and Reconciliation Commission of Canada (2012) will be announcing its Interim Report and Preliminary History, which is predicted to have a marked influence on the care of residential school survivors. In 2008, the Prime Minister of Canada, Stephen Harper, apologized to the Indigenous Peoples of Canada for the injustices that they suffered due to colonization, as an attempt to strengthen the reconciliation process between the Canadian government and Canada's Indigenous Peoples. There has been marked controversy with the TRC, as some individuals and communities do not trust a commission which is controlled by the same government which legally forced the children into residential schools (Czyzewski, 2011). Actions of the Canadian government have been in question as acknowledgement without money for programs has been viewed as an inadequate response to the historical and contemporary injustices to the Indigenous peoples of Canada.

It is noted that the First Nations are also using their Traditional song and dance and regalia at the Truth and Reconciliation Hearings, something that was totally prohibited in the schools. This is an example of how the reclamation of Tradition is occurring within the process of addressing the harm caused by the residential schools.

\section{Limitations}

Limitations of the study include the limited sample of Elders solely from the Burns Lake community. This limitation is also viewed as an opportunity for the Ts'il Kaz Koh to request program development funding as a pilot initiative. This sample limited to one First Nations community prohibits the generalization of findings to other communities until further research occurs with other communities.

Another limitation is researcher non-Indigenous status and associated implicit bias, due to my ethnicity and nationality. The use of community participatory methodology and cultural protocol helped to minimize this limitation of non-Indigenous researcher bias, but it is still inherent to this research. 


\section{Results/Findings}

Models of culturally appropriate research as described by Smith (2007) include a "power sharing model" (p. 176) in which a meaningful relationship between community and research extends beyond the research study. I have strived to act in a respectful mindful manner with the hope of beneficial outcomes within the First Nations communities in Northern BC. Defining the problem of elder abuse from the model of cultural safety reveals the multifaceted, complex nature of violence and also points the direction for future work in the removal of factors which promote the abuse, isolation of Elders, and drug and alcohol use in the community

\section{Implications and Recommendations}

Recommendations from this study include the need to further research the views of Elders surrounding violence and Elder abuse in other First Nations communities. I recommend that this research then be translated to clinical practice with the development of a culturally appropriate screening tool for First Nations Elder safety and abuse. The scope of Elder abuse in First Nations communities is currently not known. The findings from this study and future research will provide a First Nations definition of Elder abuse, as well as the identification of factors associated with Elder abuse, risk factors for Elder abuse, and preventive and treatment measures from a First Nations community perspective. Further research with other First Nations communities will allow generalization of results to be utilized in program development and evaluation.

I am mindful that any proposed changes in health policy must come from within the Ts'il Kaz Koh community and Carrier Sekani Family Services, as it is the leaders' and community members' right to determine what health policies are best for their community, under Section 11 of Indian Act (Assembly of First Nations, 2005b). Communication patterns regarding policy must be reflective of cultural respect in adherence to Carrier Sekani values and norms (Northern Health, 2005; Salois, et al., 2006; Umeda, 2002). Translation of evidence-based knowledge into policy for First Nations communities in British Columbia is performed at multiple levels, dependent on the treaty status of the Band, as well as self-determination and transfer status of health care services

This research supports the use of the health determinants model in program planning and the process of developing capacity for First Nations to control their health care services (Assembly of First Nations, 2005b). The major determinants of health which the Elders in the study described are included in the four categories of Indigenous health determinants as described by the Assembly of First Nations: Effects of colonization and Residential schools; Need for community involvement of youth and Elders; Language knowledge and use and cultural practices; and Programs to reduce and deal with alcohol and drug consumption. The Elders were very clear regarding the importance of the values of caring and respect, the role of leadership, and interconnectedness in regard to the health of the community. The importance of intergenerational relationships and the re-establishment of Traditional roles within 
community were stressed as preventive health factors related to violence and drug and alcohol use.

The Elders' views supported the importance of a strength-based approach to healing with the prior work of McCormick who found that effective healing for First Nations people must have a focus on "interconnectedness" rather than personal autonomy in order for communities to heal. The connections between individual, family, community, culture, and spirituality, and nature were all discussed by the Elders, and found by McCormick to be necessary for the healing process of First Nations people. These findings also have clinical implications for First Nations communities who can facilitate healing from injury and abuse through the blending of Traditional beliefs as well as contemporary beliefs. A strength based approach to healing from historical trauma is reinforced by this study, as the Elders have provided an abundance of resources inherent to the Ts'il Kaz Koh community. Elders discussed the healing nature of ceremonies, nature, and integration of the role of Elders and families within community programs. The Elders also described the importance of community involvement in the healing process. The Elders were very clear about the importance of blending Traditional ways into contemporary life, stressing the importance of respect for self and others and a personal responsibility to the community.

The findings of this study also support the need for funding of Youth-Elder initiatives which foster the re-establishment of intergenerational relationships and the concurrent translation of Elders' Traditional knowledge. These community initiatives act to prevent social isolation associated power differentials, and victimization of Elders. Community based drug and alcohol programs promote communal accountability and responsibility for the health of the entire community utilizing a communal structure, which supports Elder safety and prevention of exploitation for drug and alcohol funds.

Elders have expressed a desire for leadership roles within the community. One approach would be for the Chief and Tribal Council to work with the Elders to create a venue for Elder leadership on the Council and committees. Elders have suggested an Elder Safety Committee. This committee could draft a plan for Elder involvement based on Elder input. The wisdom that the Eiders bring to the health and safety of the collective of Elders and the community could act to formulate intergenerational roles.

This study recognizes the strength of these Elders and the Ts'il Kaz Koh community to deal with the historical trauma of residential schools and the effects on individual, family and community health. Based on the views of the Elders, another recommendation is the restructuring of health care within First Nations communities to support both contemporary and Traditional beliefs of health and wellness. The combination of contemporary health care and Traditional healing methods provides a holistic approach to deal with the residual problems of historical trauma and posttraumatic stress, violence, lack of parenting skills, loss of intergenerational relationships, and drug and alcohol use. These findings also support the application of the AFN Wholistic Health Planning Model (Figure 1-1) in health care restructuring (Assembly of First Nations, 2006a). As the Truth and Reconciliation Commission makes its 
recommendations, it is hoped that the Ts'il Kaz Koh will be provided resources to develop a community health model of reconciliation that bridges Traditional and contemporary healing methods. The legacy of residential schools has affected the entire Ts'il Kaz Koh community. The healing of the community will require different roles and capacities to provide the capacity to transform the entire community.

The Elders in this study have provided many lessons for us regarding the development and implementation of health programs within First Nations communities. We must be mindful as noted by Finlay, Hardy, Morris, and Nagy, (2010), that programs be culturally meaningful and sustainable, while combining Traditional and contemporary traits, values, and a range of cultural practices. A recommendation from the interviews of the Elders who described the importance of gardens in the past is the creation of a community garden space within the reserve in which Traditional food and medicinal plants could be cultivated. This garden project would integrate the harvesting, preparation and distribution of plant medicines and foods within the community and create the opportunity to translate this knowledge through intergenerational work relationships. Utilizing Elders as leaders and a source of Traditional health knowledge is part of a viable model of combining contemporary and Traditional health care practices. This model has been successful in both the Toronto Anishnawbe and Prince George Central Interior Native Health Society clinics. Other communal activities which are recommended based on Elders' interviews include hunting, fishing and preparation and distribution of meat and fish for the entire community. These activities support Traditional teachings and the passing on of oral wisdom, which strengthens the health of the entire community.

The current plans by the Ts'il Kaz Koh to build the Burns Lake Gathering Place is supported by the views of the Elders in this study. The creation of the Burns Lake Gathering Place is also in alignment with the Assembly of First Nations position regarding economic, social and cultural rights (Assembly of First Nations, 2006d). The IAF supports expanding the Assisted Living/Adult Care program to provide care for Elders residing in communities under the control of First Nations. They propose a holistic continuum of care services for Elders which are comprehensive, culturally appropriate and accessible. Promotion of community connections and care of Elders can act to promote the safety and prevention of Elder abuse.

Carrier Sekani Family Services (CSFS) provides a consortium of First Nations communities and partnerships with health care, research and educational institutions. CSFS recognizes Elder health and abuse prevention within the context of social determinants in a First Nations framework. The findings of this study can act as a baseline for future research and program development for CSFS in regard to Elder health funding and translation of Traditional knowledge, parenting classes, prevention of abuse, and re-establishment of intergenerational relationships. The findings of this study support the need for further research regarding the themes and subthemes within other First Nations communities. 
The methodology and research protocols support the need for understanding of cultural protocol in research and health care planning when working with Indigenous communities. Utilizing appropriate cultural protocol is imperative to create and maintain a respectful, mindful approach to research and programs which are centered from the community's perspectives of need in a culturally safe manner.

Plans for dissemination include the application for a Canadian Social Science and Humanities Research Council (SSHRC) Partnership Development Grant this summer with the University of Northern British Columbia (UNBC) and Carrier Sekani Family Services (CSFS), to further assess the validity of generalizing these results within the CSFS region for program development and implementation. The results of the current study will be presented at research conferences, health related meetings, and Indigenous gatherings with CSFS, Ts'il Kaz Koh (Burns Lake Band) and Elders' permission. Publication will be sought with the Elders as co-authors in both Nursing and Indigenous journals.

Margaret Kovach (2009) writes that "Everyone's experience is different, but the gift of Indigenous research frameworks is that it allows our story to be a part of our research. Research stories teach us much, they give us much. They tell us who we are as researchers, as people....stories will wait for us until we are ready. Then they will reveal themselves in purposeful, powerful ways, and when that happens we are in the midst of the sacred" (Kovach, 2009, pp. 183-184). 


\section{LIST OF REFERENCES}

Akhtar, Z. (2010). Canadian genocide and official culpability. International Criminal Law Review, 10(1), 111-135.

Assembly of First Nations. (2005a). Blueprint on Aboriginal health: Agenda for restoring and improving First Nations health. Retrieved February 7, 2012 from http://www.hc-sc.gc.ca/hcs-sss/alt formats/hpb-dgps/pdf/pubs/2005-blueprintplan-abor-auto/plan-eng.pdf

Assembly of First Nations. (2005b). First Nations health research and information action plan. Retrieved February 12, 2011 from http://64.26.129.156/cmslib/general/HRI2005711152443.pdf

Assembly of First Nations. (2005c). First Nations regional longitudinal health survey (RHS) 2002-2003; Results for adults, youth and children living in First Nations communities. Retrieved February 12, 2011 from http://www.fnigc.ca/sites/default/files/ENpdf/RHS_2002/rhs2002-03technical_report.pdf

Assembly of First Nations. (2006a). Development of a First Nations health-reporting framework. Retrieved February 23, 2011 from http://64.26.129.156/cmslib/general/FNHRF.pdf

Assembly of First Nations. (2006b). First Nations public health: A framework for improving the health of our people and our communities. Retrieved February 23, 2011 from http://64.26.129.156/cmslib/general/FNPB-IH.pdf

Assembly of First Nations. (2006c). Matrimonial real property on reserves: Our lands, our families, our solutions. Retrieved February 7, 2012 from http://www.afn.ca/uploads/files/mrp/mrp-handbook.pdf

Assembly of First Nations. (2006d). Submission to the committee on economic, social and cultural rights regarding the 5 th periodic report of Canada. Retrieved February 7, 2012 from http://www2.ohchr.org/english/bodies/cescr/docs/info-ngos/AFN.pdf

Assembly of First Nations. (2007). Reconciling First Nations and Crown jurisdiction over matrimonial real property on reserves and addressing immediate needs of First Nations families. Retrieved February 23, 2011 from http://www.afn.ca/uploads/files/mrp/juridiction-mrp.pdf

Assemby of First Nations. (2012). Description of the AFN. Retrieved March 17, 2012 from http://www.afn.ca/index.php/en/about-afn/description-of-the-afn 
Battistte, M. (2000). Reclaiming Indigenous Voice and Vision. Vancouver, BC: UBC Press.

Bennett, M. J. (1998). Basic Concepts of Intercultural Communication. Yanmouth, ME: Intercultural Press.

British Columbia Injury Research and Prevention Unit. (2007). Violence and abuse in British Columbia. Retrieved August 4, 2011 from http://www.injuryresearch.bc.ca/admin/DocUpload/3 20090616 100913Violence \%20and\%20Abuse\%20in\%20BC_FINAL.pdf

British Columbia Vital Statistics Agency. (2004). Regional analysis of health statistics for Status Indians in British Columbia, 1992-2002. Retrieved November 17, 2010 from http://www.vs.gov.bc.ca/stats/indian/indian2002/pdf/SIreport_92_02.pdf

Brown, D. (2002). Carrier Sekani self-government in context: Land and resources. Retrieved April 12, 2011 from http://geog.uvic.ca/dept/wcag/brown.pdf

Burgess, A. W., Dowdell, E. B., \& Brown, K. (2000). The elderly rape victim: Stereotypes, perpetrators, and implications for practice. Journal of Emergency Nursing, 26(5), 516-518.

Canadian Institutes of Health Research. (2007). CIHR guidelines for health research involving Aboriginal people. Retrieved August 8, 2010 from http://www.cihr-irsc.gc.ca/e/29134.html

Canadian Task Force on the Periodic Health Examination. (1994). Periodic health examination, 1994 update: 4 . Secondary prevention of elder abuse and mistreatment. Canadian Medical Association Journal, 151(10), 1413-1420.

Carney, M., Kahan, F., \& Paris, B. (2003). Elder abuse: is every bruise a sign of abuse? . Mount Sinai Journal of Medicine, 70(2), 69-74.

Carrier Sekani Tribal Council. (2007). Background. Retrieved August 21, 2011 from http://www.gov.bc.ca/arr/firstnation/carrier_sekani/default.html\#background

Carrier Sekani Tribal Council. (2010). Madate and objectives. Retrieved August 21, 2011 from http://www.csfs.org/files/mandate-and-objectives.php

Carrier Sekani Tribal Council. (2012). Ts'il Kaz Koh First Nation tradional territory [Map]. Retrieved March 8, 2012 from http://www.carriersekani.ca/images/docs/burnslake/Tsil_Kaz_Koh.pdf

Castellano, M. B. (2004). Ethics of Aboriginal research. Journal of Aboriginal Health, l(1), 98-114. 
Centers for Disease Control and Prevention. (2003). Web-based injury statistics query and reporting system. Retrieved February 7, 2012 from http://www.cdc.gov/ncipc/wisqars

Chandler, M. J., \& Lalonde, C. E. (2004). Transferring whose knowledge? Exchanging whose best practices? On knowing about Indigenous knowledge and Aboriginal suicide. Retrieved August 17, 2011 from http://web.uvic.ca/ lalonde/manuscripts/2003INAC.pdf

Changfoot, N. (2009). Canada's truth and reconciliation commission for Indian residential schools: Whose truth? Whose reconciliation? Paper presented at the Canadian Political Science Association Annual Conference, Ottowa, Canada.

Christopher, S., Watts, V., McCormick, A., \& Young, S. (2008). Building and maintaining trust in a community-based participatory research partnership. Framing Health Matters, 98(8), 1398-1406.

Crocker, L. (2005). Strength and resiliency in the narratives of Margaret Gagnon (unpublished master's thesis). Prince George, B.C.: University of Northern British Columbia.

Crukshank, J. (1990). Life lived like a story. Lincoln, NE: University of Nebraska Press.

Czyzewski, K. (2011). The Truth and Reconciliation Commission of Canada: Insights in the goal of transformative education. Retrieved November 16, 2011 from http://ir.lib.uwo.ca/cgi/viewcontent.cgi?article $=1026 \&$ context=iipj

Driscoll, L., \& Jackson, C. (2007). What makes First Nations communities successful? Retrieved May 16, 2010 from http://www.hc-sc.gc.ca/sr-sr/pubs/hprrpms/bull/2007-people-place-gens-lieux/first-nations-autochtones-eng.php

Etienne, M., \& Leacock, E. (1980). Women and colonization. Brooklyn, NY: JF Bergin Publishers.

Finlay, J., Hardy, M., Morris, D., \& Nagy, A. (2010). Mamow Ki-ken-da-ma-win: A Partnership Approach to Child, Youth, Family and Community Wellbeing. International Journal of Mental Health and Addiction, 8(2), 245-257.

First Nations Governance Committee. (2005). First Nations regional longitudinal health survey (RHS) 2002-2003; Results for adults, youth and children living in First Nations communities. Retrieved May 24, 2011 from http://www.rhsers.ca/sites/default/files/ENpdf/RHS 2002/rhs2002-03-technical_report.pdf

Fisher, J. W., \& Dyer, C. B. (2003). The hidden health menace of elder abuse. Physicians can help patients surmount intimate partner violence. Postgraduate Medicine, $113(4), 21-24,30$. 
Health Canada. (1994). Abuse and neglect of older adults: Awareness information for people in the workplace. Retrieved February 11, 2012 from http://publications.gc.ca/collections/Collection/H72-21-120-1994E.pdf

Health Canada. (1996). Trends in First Nations Mortality 1979-1993 [Figure 10]. Retrieved November 7, 2011 from http://www.hc-sc.gc.ca/fniahspnia/pubs/promotion/_injury-bless/2001 trauma/index-eng.php\#figure10

Health Canada. (2001). Unintentional and intentional injury profile for Aboriginal people in Canada, 1996-1997 [Figure 5]. Retrieved November 7, 2011 from http://www.hc-sc.gc.ca/fniah-spnia/pubs/promotion/ injurybless/2001 trauma/index-eng.php\#figure5

Health Canada. (2005). First Nations comparable health indicators. Retrieved November 7, 2011 from http://www.hc-sc.gc.ca/fniah-spnia/diseasesmaladies/2005-01 health-sante indicat-eng.php

Health Canada. (2006). Community awareness and response: Abuse and neglect of older adults. Retrieved November 12, 2011 from http://www.phac-aspc.gc.ca/ncfvcnivf/publications/agecommuni-eng.php

Health Canada. (2009). A statistical profile on the health of First Nations in Canada: Determinants of health, 1999 to 2003. Retrieved November 7, 2011 from http://www.hc-sc.gc.ca/fniah-spnia/pubs/aborig-autoch/2009-stats-profil/indexeng.php

Holkup, P. A., Tripp-Reimer, T., Salois, E. M., \& Weinert, C. (2004). Community-based participatory research: an approach to intervention research with a Native American community. Advances in Nursing Science, 27(3), 162-175.

Indian and Northern Affairs Canada. (2006). Registered Indian demography, population, household and family projections, 2004-2029. Retrieved February 7, 2012 from http://www.aadnc-aandc.gc.ca/DAM/DAM-INTER-HQ/STAGING/textetext/rgd 1100100016839 eng.pdf

Indian and Northern Affairs Canada. (2010). Aboriginal peoples and communities.

Retrieved January 19, 2011 from http://www.aadnc-aandc.gc.ca/eng/1100100013785

Kahan, F., \& Paris, B. (2003). Why elder abuse continues to elude the health care system. Mount Sinai Journal of Medicine, 70(1), 62-68.

Kirmayer, L. J., \& Walaskakis, G. G. (2009). Healing traditions: The mental health of Aboriginal peoples in Canada. Vancouver, BC: UBC Press. 
Kovach, M. (2009). Indigenous methodologies, characteristics, conversations, and contexts. Toronto, ON: University of Toronto Press Incorporated.

Krueger, P., \& Patterson, C. (1997). Detecting and managing elder abuse: challenges in primary care. Canadian Medical Association Journal, 157(8), 1095-1100.

Kuwayama, T. (2004). Native anthropology. Melbourne, Victoria: Trans Pacific Press.

Laneui, P. (2000). Jagged worldviews colliding. In M. Battiste (Ed.), Reclaiming Indigenous Voice and Vision (pp. 150-160). Vancouver, BC: UBC Press.

Little Bear, L. (2000). Jagged wordviews colliding. In M. Battistte (Ed.), Reclaiming Indigenous voice and vision. Vancouver, BC: UBC Press.

McCormick, R. (1994). The facilitation of healing for the First Nations people of British Columbia (unpublished dissertation). Vancouver, BC: University of British Columbia.

McCormick, R. (2009). Improving access to mental health and addictions services. Retrieved August 17, 2010 from http://aboriginalhealth.vch.ca/docs/forum09/2009 10 mccormick improving acc ess_mha_services.pdf

McDonald, D. (2007). First Nations, residential schools, and the Americanization of the holocaust: Rewriting Indigenous history in the United States and Canada. Canadian Journal of Political Science / Revue canadienne de science politique, 40(4), 995-1015.

National Center for Injury Prevention and Control. (2001). CDC Injury Fact Book. Atlanta, GA: Centers for Disease Control and Prevention.

National Center on Elder Abuse. (1999). Elder abuse information series number 1: Types of elder abuse in domestic settings. Retrieved June 20, 2011 from http://www.ncea.aoa.gov/Main_Site/pdf/basics/fact1.pdf

Northern Health. (2005). Aboriginal health planning and information guide. Prince George, BC: Northern Health.

Office of the Provincial Officer of British Columbia. (2009). Pathways to health and healing: Second report on the health and well-being of Aboriginal people in British Columbia. Retrieved February 7, 2012 from http://www.health.gov.bc.ca/pho/pdf/abohlth11-var7.pdf

Patton, M. (2002). Qualitative research and evaluation methods. Thousand Oaks, CA: Sage. 
Posey, D. (2004). Indigenous knowledge and ethics. New York: Rutledge.

Public Health Agency of Canada. (1999). Measuring up - A health surveillance update on Canadian children and youth. Retrieved August 21, 2010 from http://www.phac-aspc.gc.ca/publicat/meas-haut/mu_y-eng.php

Public Health Agency of Canada. (2005). Consultations on public health goals for Canada. Retrieved August 21, 2010 from file:///C:/Users/gspake/AppData/Local/Temp/summ-2e.html

Royal Commission on Aboriginal People. (2006). Report of the Royal Commission on Aboriginal People: Appendix E: Ethical guidelines for research. Retrieved March 28, 2012 from http://www.collectionscanada.gc.ca/webarchives/20071124125036/http://www.ai nc-inac.gc.ca/ch/rcap/sg/ska5e e.html\#Appendix\%20E:\%20Ethical \%20Guidelines\%20for\%20Research

Salois, E. M., Holkup, P. A., Tripp-Reimer, T., \& Weinert, C. (2006). Research as spiritual covenant. Western Journal of Nursing Research, 28(5), 505-524.

Saveman, B. I., Hallberg, A., \& Norberg, I. (1992). The problems of dealing with abuse and neglect of the elderly: Interviews with District nurses. Qualitative Health Research, 2(3), 302-307.

Smith, A. (2005). Conquest, sexual violence, and American Indian genocide. Cambridge, MA: South End Press.

Smith, D., Varcoe, C., \& Edwards, N. (2005). Turning around the intergenerational impact of residential schools on Aboriginal People: Implications for health policy and practice. Canadian Journal of Nursing Research, 37(4), 38-60.

Smith, L. (2007). Decolonizing methodologies research and Indigenous peoples. New York: St. Martin's Press.

Statistics Canada. (2006). Measuring Violence Against Women: Statistical Trends 2006 [Figure 50]. Retrieved October 11, 2010 from http://www.unece.org/fileadmin/DAM/stats/gender/vaw/surveys/Canada/2006_Pu blication VAW.pdf

Tervalon, M., \& Murray-Garcia, J. (1998). Cultural humility versus cultural competence: A critical distinction in defining physician training outcomes in multicultural education. Journal of Health Care for the Poor and Underserved, 9(2), 117-124.

Tietelman, J. L., \& Copolilio, A. (2002). Sexual abuse among persons with Alzheimer's disease: Guidelines for recognition and intervention. Alzheimer's Care Quarterly, $3(3), 252-258$. 
Truth and Reconciliation Commission of Canada. (2012). Mandate of the Truth and Reconciliation Commission of Canada. Retrieved March 17, 2010 from http://www.myrobust.com/websites/trcinstitution/index.php? $\mathrm{p}=7$

Umeda, M. (2002). Spirituality in helping others: Learning from First Nations Elders and counselor' alcohol related experience (Unpublished master's thesis). British Columbia, BC: University of Northern British Columbia.

Villegas, M., Neugegauer, S. R., \& Venegas, K. R. (2008). Indigenous knowledge and education: Sites of struggles, strength, and survivance. Cambridge, MA: Harvard Educational Review.

Wilson, S. (2008). Research is ceremony: Indigenous research methods. Halifax, Nova Scotia: Fernwood.

Wong, C., \& Marr, S. (2002). Factors influencing health-care professionals in identifying and managing elder abuse: a preliminary report. Geriatrics Today, 5, 34-37.

World Health Organization. (2001). International decade of the world's Indigenous people (WHO Publication No. WHA54.16). Retrieved February 12, 2012 from http://www.who.int/hhr/WHA54.16\%20Indigenous\%20Decade.pdf

World Health Organization. (2002). World report on violence and health outline. Retrieved June 24, 2011 from http://www.who.int/violence_injury_prevention/violence/world_report/en/summa ry en.pdf

World Health Organization. (2006). Basic Documents: (WHO Publication Forty-fifth edition, Supplement, October). Retrieved November 6, 2010 from http://www.who.int/governance/eb/who_constitution_en.pdf

Yazzie, R. (2000). Indigenous Peoples and Postcolonial Colonialism In M. Battiste (Ed.), Reclaiming Indigenous voice and vision (pp. 39-49). Vancouver, BC: UBC Press.

Yuan, N. P., Koss, M. P., Polacca, M., \& Goldman, D. (2006). Risk factors for physical assault and rape among six Native American tribes. Journal of Interpersonal Violence, 21(12), 1566-1590. 


\section{APPENDIX A. INSTITUTIONAL REVIEW BOARD APPROVAL FROM THE UNIVERSITY OF TENNESSEE HEALTH SCIENCE CENTER}

\begin{tabular}{lr}
\hline THE UNIVERSITY OF TENNESSEE \\
Health Science Center
\end{tabular}

January 12, 2011

Eileen Alanna Owen-williams, DNP

UTHSC - CON - Nursing- Academic Programs

Re: 10-00970-XP

Study Title: Traditional Roles of Caring for Elders: Views from First Nations Elders Regarding

Health, Violence, and Elder Abuse.

Dear Dr. Owen-Williams:

The Administrative Section of the UTHSC Institutional Review Board (IRB) has received your written acceptance of and/or response dated 01/03/2011 12:10:29 AM CST to the provisos outlined in our correspondence of $9 / 10 / 2010$ concerning the above referenced project. The IRB determined that your application is eligible for expedited review under categories (6) and (7). The IRB has reviewed these materials and determined that they do comply with proper consideration for the rights and welfare of human subjects and the regulatory requirements for the protection of human subjects. Therefore, this letter constitutes full approval by the IRB of your application as submitted. Because this study is not being conducted here and subjects will not be recruited locally, the UTHSC IRB has not reviewed the informed consent documents. Rather, the UTHSC accepts the approval of the University of British Columbia's REB of the individual and community consent forms. This study was approved for 12 months with an expiration date of 09/10/2011.

This study may not be initiated until you receive approval from the institution(s) where the research is being conducted.

In the event that subjects are to be recruited using solicitation materials, such as brochures, posters, web-based advertisements, etc., these materials must receive prior approval of the IRB. Any revisions in the approved application must also be submitted to and approved by the IRB prior to implementation. In addition, you are responsible for reporting any unanticipated serious adverse events or other problems involving risks to subjects or others in the manner required by the local IRB policy.

Finally, re-approval of your project is required by the $\mathbb{R} B$ in accord with the conditions specified above. You may not continue the research study beyond the time or other limits specified unless you obtain prior written approval of the IRB.

Sincerely,

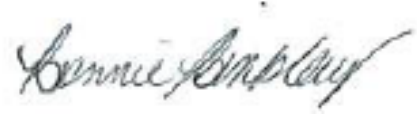

Page 1 of 2 
Signature applied by Bonnie L Binkley on 01/12/2011 04:21:57 PM CST

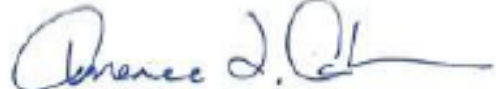

Signature applied by Terrence F Ackerman on 01/12/2011 04:23:46 PM CST

Bonnie Binkley, MA, CIM, CIP

Regulatory Specialist

UTHSC IRB
Terrence F. Ackerman, $\mathrm{Ph}$ D.

Chairman

UTHSC IRB 


\title{
APPENDIX B. RESEARCH ETHICS BOARD APPROVAL FROM THE UNIVERSITY OF NORTHERN BRITISH COLUMBIA
}

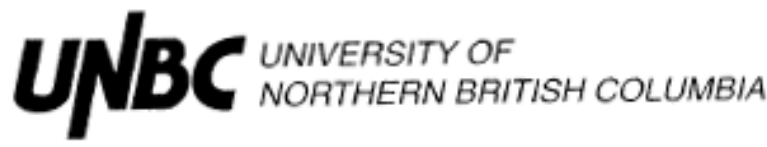

\author{
RESEARCH ETHICS BOARD
}

\section{MEMORANDUM}

\author{
To: $\quad$ Eileen Owen-Williams \\ From: Henry Harder, Chair \\ Research Ethics Board \\ Date: $\quad$ December 17, 2010 \\ Re: $\quad$ E2010.1019.158 \\ The Traditional Roles of Caring for Elders: Views form First Nations Elders \\ Regarding Health, Violence and Elder Abuse
}

Thank you for submitting the above-noted proposal with amendments to the Research Ethics Board. Your proposal has now been approved.

We are pleased to issue approval for the above named study for a period of 12 months from the date of this letter. Continuation beyond that date will require further review and renewal of REB approval. Any changes or amendments to the protocol or consent form must be approved by the Research Ethics Board.

Good luck with your research.

Sincerely,

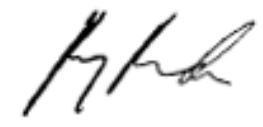

Henry Harder 


\section{APPENDIX C. INTERVIEW QUESTIONS}

The following questions were used as a guideline in the interviews of the Ts'il Kaz Koh Elders.

1. I would like you to think about being an Elder in your community and help me understand what that means to you.

2. Could you describe for me, what family and community relationships were like prior to Contact?

3. Can you please describe how families cared for Elders in the past?

4. For some people, the relationships that they have with family, friends, and others can be very important to them and their health. Please help me to understand how best to work with families in which Elders are experiencing violence or neglect.

5. Help me to understand how you think violence affects Elders in your community.

6. What Elders' strengths can be brought into the healing of violence in your community?

7. How can we help Elders stay in their communities and remain safe and protected? 


\section{VITA}

Eileen A. Owen-Williams was born in Spokane, Washington in 1954. She graduated from Washington State University with a Baccalaureate of Science in Nursing in 1976. Eileen received her Masters of Science in Nursing at the University of Washington in 1983 with a clinical focus as a Family Nurse Practitioner. Eileen also studied at the University of California at San Diego and the Oregon Health Sciences University in Nurse Midwifery and received a post-Master's certificate in 1989.

Eileen was accepted into the doctoral program at The University of Tennessee Health Science Center in 2003 and received a Doctorate of Nursing Practice in December of 2005 with a specialty focus in Forensic Nursing. She was accepted into doctoral studies with The University of Tennessee Health Science Center College of Graduate Health Sciences in 2006 and will graduate in May 2012 with a Doctor of Philosophy in Nursing. 